\title{
The Detection of Inter-Turn Short Circuits in the Stator Windings of Sensorless Operating Induction Motors
}

\author{
Jean Blaise Teguia ${ }^{1,2 *}$, Godpromesse Kenne ${ }^{2}$, Alain Tewa Soup Kammogne ${ }^{1}$, \\ Georges Collince Fouokeng1, Arnaud Nanfak ${ }^{3}$
}

\author{
${ }^{1}$ Unité de Recherche de Matière Condensée, d’Electronique et de Traitement de Signal (UR-MACETS), Département de Physique, \\ Faculté des Sciences, Université de Dschang, Dschang, Cameroun \\ ${ }^{2}$ Unité de Recherche d'Automatique et d'Informatique Appliquée (UR-AIA), Département de Génie Electrique IUT FOTSO \\ Victor Bandjoun, Université de Dschang, Bandjoun, Cameroun \\ ${ }^{3}$ Laboratoire Energie, Matériaux, Modélisation et Méthodes (LE3M), Ecole Nationale Supérieure Polytechnique de Douala, \\ Université de Douala, Douala, Cameroun \\ Email: *jeanblaiseteguia@gmail.com
}

How to cite this paper: Teguia, J.B., Kenne, G., Kammogne, A.T.S., Fouokeng, G.C. and Nanfak, A. (2021) The Detection of InterTurn Short Circuits in the Stator Windings of Sensorless Operating Induction Motors. World Journal of Engineering and Technology, 9, 653-681.

https://doi.org/10.4236/wjet.2021.93046

Received: May 7, 2021

Accepted: August 22, 2021

Published: August 25, 2021

Copyright $\odot 2021$ by author(s) and Scientific Research Publishing Inc. This work is licensed under the Creative Commons Attribution International License (CC BY 4.0).

http://creativecommons.org/licenses/by/4.0/

\section{(c) (i) Open Access}

\begin{abstract}
This work proposes an alternative strategy to the use of a speed sensor in the implementation of active and reactive power based model reference adaptive system (PQ-MRAS) estimator in order to calculate the rotor and stator resistances of an induction motor (IM) and the use of these parameters for the detection of inter-turn short circuits (ITSC) faults in the stator of this motor. The rotor and stator resistance estimation part of the IM is performed by the PQ-MRAS method in which the rotor angular velocity is reconstructed from the interconnected high gain observer (IHGO). The ITSC fault detection part is done by the derivation of stator resistance estimated by the PQMRAS estimator. In addition to the speed sensorless detection of ITSC faults of the IM, an approach to determine the number of shorted turns based on the difference between the phase current of the healthy and faulty machine is proposed. Simulation results obtained from the MATLAB/Simulink platform have shown that the PQ-MRAS estimator using an interconnected highgain observer gives very similar results to those using the speed sensor. The estimation errors in the cases of speed variation and load torque are almost identical. Variations in stator and rotor resistances influence the performance of the observer and lead to poor estimation of the rotor resistance. The results of ITSC fault detection using IHGO are very similar to the results in the literature using the same diagnostic approach with a speed sensor.
\end{abstract}




\section{Keywords}

Inter-Turn Short Circuits, Active and Reactive Power Based Model Reference Adaptive System, Interconnected High Gain Observer, Fault Detection

\section{Introduction}

The induction motors (IM) have been widely used in various industrial applications requiring variable speed because they are simple in construction, low cost, very reliable, and very robust and require minimal maintenance [1] [2]. Nowadays industrial technology requires the knowledge of the actual values of IM parameters for high performance and precision operation of the cause [3]. Since the estimation of IM parameters has several purposes, such as drive performance, condition monitoring and fault detection, the modern controls such as direct torque control (DTC) or direct field-oriented control (DFOC) require information about the internal state such as electromagnetic flux or electromagnetic torque cannot be measured directly, so they are estimated [4]. It is then found out that the estimation of the internal state is sensitive to the IM parameters and how the wrong estimation of these parameters has a direct consequence on the drive performance. Consequently, the idea of fault detection is that, the parameters fluctuations can indicate a fault symptom and the monitoring of these parameters values can be used as indicators of condition monitoring of this method. Among all the IM parameters, the most important are stator and rotor resistances which have been shown to vary up to $50 \%$ and $100 \%$ of their nominal values during their operation due the effects of the temperature rise, skin effect and flux saturation [5] [6].

With the goal to optimize the IM parameters estimation, several methods have been developed this last decade including off-line estimators and on-line estimators. Namely, the authors demonstrated in Refs. [7] and [8] that off-line estimators conducted during the commissioning session include the standard methods for the estimation such as blocked rotor test, full-load test, no-load test and standstill frequency response test. They also show that from the three major types of on-line IM estimators (spectral analysis techniques, observer-based techniques and the model reference adaptive system-based techniques), the parameters can be calculated during the normal operation of the IM and provide a real time estimation [4] [9]. On the other hand, the model reference adaptive system (MRAS)-based techniques have shown to be more attractive techniques due to its simple structure and easy implementation [3] [4] and [10]. This model is used in order to adjust the parameters through an adaptive mechanism. The idea of this on-line estimation approach relies on the minimization of the error between the reference and adjustable model by an adaptive mechanism [11]. Several types of MRAS-based estimators have been proposed in literature: electromagnetic fluxbased (F-MRAS) [12], reactive power-based (Q-MRAS) [13], active power-based 
(P-MRAS) [14], X based (X-MRAS) [15], PY based (PY-MRAS) [16], Electromagnetic torque (T-MRAS) [17] and back electromagnetic force (back-EMF MRAS) [18].

Some authors presented an active and reactive power based MRAS (PQ-MRAS) estimator of both stator and rotor resistances with significant results [3]. The implementation of this estimator requires the use of a speed sensor. In most cases, there is physically no space to add a speed sensor on the rotor axis of the motor already installed in its operating environment. Moreover, the speed sensor is unreliable because it is sensitive to external disturbances. Its presence generates an increase in the cost of the order (maintenance cost in case of sensor failure), the complexity of the installation which is an important challenge of this work. An important technic to overcome the perturbations and fluctuations affecting the sensor is the use of the observer (software sensor) which allows to deal with the absence of the mechanical sensor by giving the information of the speed and the load torque by means of the unique measurement of the currents [19]. Two basic approaches to synthesizing observers: a) The heuristic approach close to artificial intelligence (neural network) [20] [21], b) The approach based on the geometry of the machine (introduction of harmonics as functions of the speed of the machine [22] [23]. There are several categories of observers used to avoid difficulties in estimating state variables at low speed such as the extended Kalman filters [22] [24], the extended Luenberger filters [24]; adaptive observers [25]; slippery mode observers [26]; cascade observers and interconnected high gain observers [27] [28].

The scope of this paper falls into the faults detection under sensorless speed control technology. Facing these challenges previously established, the main contributions of this paper are three fold:

1) Minimizing the costs of implementation and maintenance by reducing the number of sensors.

2) Use of IHGO to estimate the rotor speed of the IM in the implementation of PQ-MRAS estimator,

3) Detect ITSC stator faults using simple estimated resistance derivation algorithms.

The observers used in this work are of the interconnected high-gain observer (IHGO) type. This paper proposes to combine the two methods where the IHGO is used to estimate speed rotor and PQ-MRAS for the estimation of stator and rotor resistances. The stator resistance estimated is utilized in faults detection algorithms, which is based on a simple assumption: inter-turn short circuit (ITSC) results in a sharp decrease of the estimated stator resistance [29]. Studies were performed in the closed-loop control system based on Direct Rotor Field Oriented Control (DRFOC) structure.

The remaining parts of this paper are organized as follows: the mathematical model of the IM, the formulation of the IHGO, the PQ-MRAS estimator description, the direct field oriented control structure of IM and the fault diagnosis strat- 
egy are presented in section 2; the simulation results are presented in Section 3. The results comparison is presented in section 4 and finally conclusions and remarks are made in Section 5.

\section{Description and Modelling of Systems Components}

Test and validations of faults detection by parameter estimation require a model suited for fault modelling. For this purpose, it is presented, in this section, a model of IM dedicated to inter-turns short-circuit winding faults. The IGHO technique will make it possible to reconstruct the rotational speed of the rotor which will be immediately used through the PQ-MRAS technique to estimate the resistance of the stator and of the rotor using the measurement of the current and the voltage of the stator. In this section, the control structure and the diagnosis fault strategy are also presented.

\subsection{The IM Model}

The model used is that of [30], allowing the decoupling of two modes, the common and the differential modes. It is composed of an additional shorted winding in a three-phase axis. Figure 1 shows a three phase two-pole induction machine in case of a short-circuit winding at phase b. This fault induces in stator a new windings $B_{c c}$ short circuited and localized according to first phase by the angle $\theta_{c c}=2 \pi / 3 \mathrm{rad} . \theta_{c c_{k}}$ and $\eta_{c c_{k}}$ are stator faults parameters where,

1) the localization parameter $\theta_{c c_{k}}$ can takes only the three values: $0,2 \pi / 3$ or $4 \pi / 3$, corresponding to the short-circuit on the stator phase $\mathrm{a}, \mathrm{b}$ or $\mathrm{c}$, respectively.

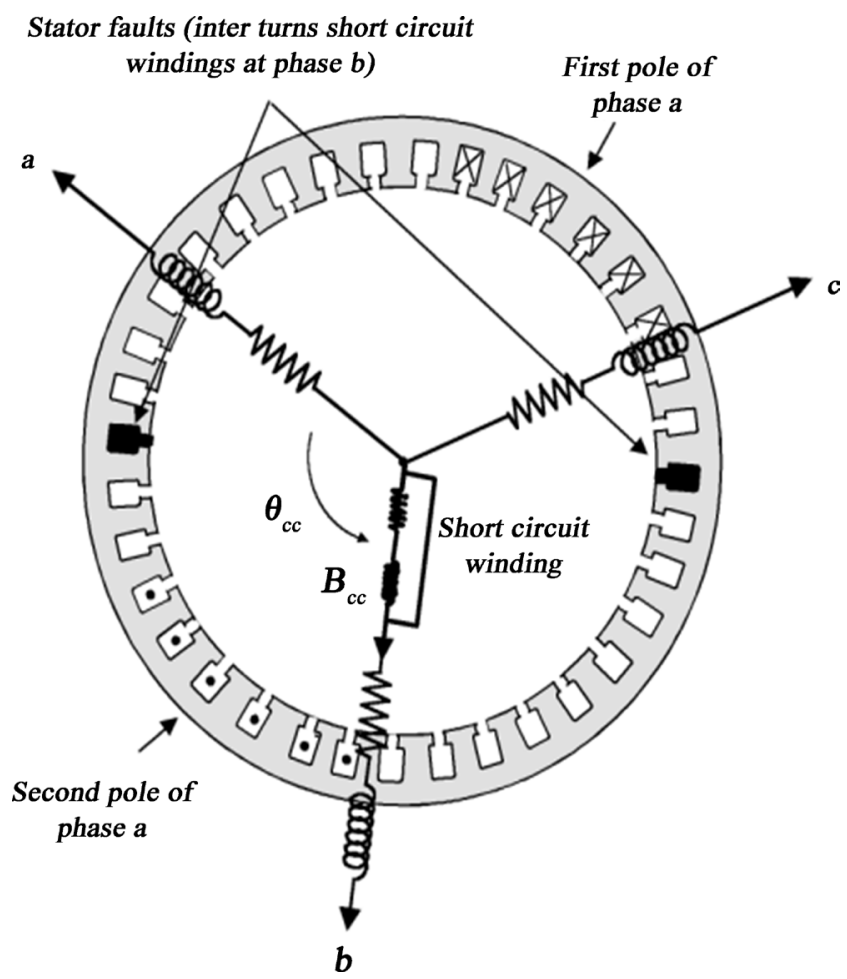

Figure 1. Three phase stator winding scheme with an ITSC fault in phase $b$ [30]. 
2) the detection parameter $\eta_{c c_{k}}$ which allows to quantify the unbalance, is equal to the ratio between the number of inter-turn short-circuit windings $\left(N_{c c_{k}}\right)$ and the total number of inter turns in one healthy phase $\left(N_{s}\right)$.

\subsubsection{Short-Circuit Model}

In the stator faulty case, an additional shorted circuit winding $B_{c c}$ appears in stator. This winding creates a stationary magnetic field $H_{c c}$ oriented according to the faulty winding [30]. Thus, we define the short-circuit current $i_{c c}$ into interturn short-circuit winding at origin of a short-circuit flux $\varphi_{c c}$. Voltage and flux equations for faulty model of induction machine with global-leakage inductance referred to the stator can be written as

$$
\left\{\begin{array}{l}
u_{s}=\left[R_{s}\right] i_{s}+\frac{\mathrm{d}}{\mathrm{d} t} \phi_{s} \\
0=\left[R_{r}\right] i_{r}+\frac{\mathrm{d}}{\mathrm{d} t} \phi_{r} \\
0=R_{c c} i_{c c}+\frac{\mathrm{d}}{\mathrm{d} t} \phi_{c c} \\
\phi_{s}=\left[L_{s}\right] i_{s}+\left[M_{s r}\right] i_{r}+\left[M_{s c c}\right] i_{c c} \\
\phi_{r}=\left[L_{r}\right] i_{r}+\left[M_{r s}\right] i_{s}+\left[M_{r c c}\right] i_{c c} \\
\phi_{c c}=\left[M_{s c c}\right] i_{s}+\left[M_{c c r}\right] i_{r}+L_{c c} i_{c c}
\end{array}\right.
$$

where $u_{s}$ represents the stator voltage, $i_{s}, i_{r}$ and $i_{c c}$ are the stator, rotor, and short-circuit currents respectively. $\phi_{s}, \phi_{r}$ and $\phi_{c c}$ denotes the stator, rotor, and short-circuit flux respectively.

$$
\left[R_{s}\right]=\left[\begin{array}{ccc}
R_{s} & 0 & 0 \\
0 & R_{s} & 0 \\
0 & 0 & R_{s}
\end{array}\right] \text { and }\left[R_{r}\right]=\left[\begin{array}{ccc}
R_{r} & 0 & 0 \\
0 & R_{r} & 0 \\
0 & 0 & R_{r}
\end{array}\right] \text { are the stator and rotor re- }
$$

sistances respectively while $R_{c c}=\eta_{c c} \cdot R_{s}$ represents the short-circuit resistance with

$$
\eta_{c c}=\frac{\text { Number of interturns short-circuit windings }}{\text { Total number of interturns in healthy phase }}=\frac{N_{c c}}{N_{s}}
$$

With respect to the stator and rotor, we define the following matrices for the inductors:

$$
\begin{gathered}
{\left[L_{s}\right]=\left[\begin{array}{ccc}
L_{m}+L_{f} & -\frac{L_{m}}{2} & -\frac{L_{m}}{2} \\
-\frac{L_{m}}{2} & L_{m}+L_{f} & -\frac{L_{m}}{2} \\
-\frac{L_{m}}{2} & -\frac{L_{m}}{2} & L_{m}+L_{f}
\end{array}\right], \quad\left[L_{r}\right]=\left[\begin{array}{ccc}
L_{m} & -\frac{L_{m}}{2} & -\frac{L_{m}}{2} \\
-\frac{L_{m}}{2} & L_{m} & -\frac{L_{m}}{2} \\
-\frac{L_{m}}{2} & -\frac{L_{m}}{2} & L_{m}
\end{array}\right] ; L_{c c}=\eta_{c c}^{2}\left(L_{m}+L_{f}\right)} \\
{\left[M_{s r}\right]=L_{p}\left[\begin{array}{ccc}
\cos (\theta) & \cos \left(\theta+\frac{2 \pi}{3}\right) & \cos \left(\theta-\frac{2 \pi}{3}\right) \\
\cos \left(\theta-\frac{2 \pi}{3}\right) & \cos \left(\theta+\frac{2 \pi}{3}\right) \\
\cos \left(\theta+\frac{2 \pi}{3}\right) & \cos \left(\theta-\frac{2 \pi}{3}\right) & \cos (\theta)
\end{array}\right]}
\end{gathered}
$$




$$
\begin{aligned}
{\left[M_{s c c}\right]=\eta_{c c} L_{p}\left[\begin{array}{c}
\cos \left(\theta_{c c}\right) \\
\cos \left(\theta_{c c}-\frac{2 \pi}{3}\right) \\
\cos \left(\theta_{c c}+\frac{2 \pi}{3}\right)
\end{array}\right],\left[M_{r c c}\right]=\eta_{c c} L_{p}\left[\begin{array}{c}
\cos \left(\theta_{c c}-\theta\right) \\
\cos \left(\theta_{c c}-\theta-\frac{2 \pi}{3}\right) \\
\cos \left(\theta_{c c}-\theta+\frac{2 \pi}{3}\right)
\end{array}\right] } \\
{\left[M_{s r}\right]=\left[M_{r s}\right]^{\mathrm{T}},\left[M_{c c s}\right]=\left[M_{s c c}\right]^{\mathrm{T}},\left[M_{c c r}\right]=\left[M_{r c c}\right]^{\mathrm{T}} }
\end{aligned}
$$

$\theta$ stand as the rotor angular position. $L_{p}$ and $L_{f}$ are, respectively, principal and global-leakage inductance referred to the stator.

\subsubsection{Two-Phases Stator Faulty Induction Model}

To minimize the number of model variables, we use Concordia transformation, which gives $(\alpha, \beta)$ values of same amplitude as $(a, b, c)$ ones. Thus, we define three- to two-axis transformation $T_{23}$ as

$$
\left\{\begin{array}{l}
\underline{x}_{\alpha \beta_{r}}=P(\theta) \cdot T_{23} \cdot \underline{x}_{r} \\
\underline{x}_{\alpha \beta_{s}}=T_{23} \underline{x}_{s}
\end{array}\right.
$$

where $\underline{X}_{\alpha \beta}$ is projection of $\underline{x}$ following $\alpha$ and $\beta$ axis. The transformation matrix and the rotational matrix are defined respectively as follows:

$$
\begin{gathered}
T_{23}=\left[\begin{array}{lll}
\cos (0) & \cos \left(\frac{2 \pi}{3}\right) & \cos \left(\frac{2 \pi}{3}\right) \\
\sin (0) & \sin \left(\frac{2 \pi}{3}\right) & \sin \left(\frac{2 \pi}{3}\right)
\end{array}\right] \\
P(\theta)=\left[\begin{array}{ll}
\cos (\theta) & \cos \left(\theta+\frac{\pi}{2}\right) \\
\sin (\theta) & \sin \left(\theta+\frac{\pi}{2}\right)
\end{array}\right]
\end{gathered}
$$

The short-circuit variables are localized on one axis, these projection on the two Concordia axis $\alpha$ and $\beta$ is defined as

$$
\underline{i}_{\alpha \beta_{c c}}=\left[\begin{array}{c}
\cos \left(\theta_{c c}\right) \\
\sin \left(\theta_{c c}\right)
\end{array}\right] \cdot i_{c c}, \quad \underline{\phi}_{\alpha \beta_{c c}}=\left[\begin{array}{c}
\cos \left(\theta_{c c}\right) \\
\sin \left(\theta_{c c}\right)
\end{array}\right] \cdot \phi_{c c}
$$

Thus, (1) becomes

$$
\left\{\begin{array}{l}
\underline{u}_{\alpha \beta_{s}}=R_{s} \underline{i}_{\alpha \beta_{s}}+\frac{\mathrm{d}}{\mathrm{d} t} \underline{\phi}_{\alpha \beta_{s}} \\
\underline{\phi}_{\alpha \beta_{s}}=L_{m}\left(\underline{i}_{\alpha \beta_{s}}+\underline{i}_{\alpha \beta_{r}}+\sqrt{\frac{2}{3}} \eta_{c c}-\alpha \beta_{c c}\right)+L_{f} \underline{i}_{-\alpha \beta_{s}} \\
\underline{u}_{\alpha \beta_{r}}=0=R_{r} \cdot \underline{i}_{\alpha \beta_{r}}+\frac{\mathrm{d}}{\mathrm{d} t} \underline{\phi}_{\alpha \beta_{r}}-\omega \cdot P\left(\frac{\pi}{2}\right) \underline{\phi}_{\alpha \beta_{r}} \\
\underline{\phi}_{\alpha \beta_{r}}=L_{m}\left(\underline{i}_{\alpha \beta_{s}}+\underline{i}_{\alpha \beta_{r}}+\sqrt{\frac{2}{3}} \eta_{c c} \underline{i}_{\alpha \beta_{c c}}\right) \\
0=\eta_{c c} R_{s} \underline{i}_{\alpha \beta_{c c}}+\frac{\mathrm{d}}{\mathrm{d} t} \underline{\phi}_{\alpha \beta_{c c}} \\
\underline{\phi}_{\alpha \beta_{c c}}=\sqrt{\frac{2}{3}} \eta_{c c} L_{m} Q\left(\theta_{c c}\right)\left(\underline{i}_{-\alpha \beta_{s}}+\underline{i}_{\alpha \beta_{r}}\right)+\left(\frac{2}{3} L_{m}+L_{f}\right) \eta_{c c}^{2} i_{\alpha \beta_{c c}}
\end{array}\right.
$$


where $\omega$ is the rotor electrical frequency; $L_{m}=(3 / 2) L_{p}$ the magnetizing inductance. $Q\left(\theta_{c c}\right)$ is define as:

$$
Q\left(\theta_{c c}\right)=\left[\begin{array}{cc}
\cos ^{2}\left(\theta_{c c}\right) & \cos \left(\theta_{c c}\right) \sin \left(\theta_{c c}\right) \\
\cos \left(\theta_{c c}\right) \sin \left(\theta_{c c}\right) & \sin ^{2}\left(\theta_{c c}\right)
\end{array}\right]
$$

If we neglect $L_{f}$ according to $L_{m}$ in short-circuit flux expression (7), we can write new flux equations as:

$$
\left\{\begin{array}{l}
\underline{\phi}_{\alpha \beta_{s}}=\underline{\phi}_{\alpha \beta_{m}}+\underline{\phi}_{\alpha \beta_{f}}=L_{m}\left(\underline{i}_{\alpha \beta_{s}}+\underline{i}_{\alpha \beta_{r}}-\underline{\tilde{i}}_{\alpha \beta_{c c}}\right)+L_{f} \underline{i}_{\alpha \beta_{s}} \\
\underline{\phi}_{\alpha \beta_{r}}=\underline{\phi}_{\alpha \beta_{m}}=L_{m}\left(\underline{i}_{\alpha \beta_{s}}+\underline{i}_{\alpha \beta_{r}}-\underline{\tilde{i}}_{\alpha \beta_{c c}}\right) \\
\underline{\tilde{\phi}}_{\alpha \beta_{c c}}=\eta_{c c} Q\left(\theta_{c c}\right) \underline{\phi}_{\alpha \beta_{m}}
\end{array}\right.
$$

where

$$
\left\{\begin{array}{l}
\tilde{\underline{i}}_{\alpha \beta_{c c}}=-\sqrt{\frac{2}{3}} \eta_{c c} i_{\alpha \beta_{c c}} \\
\tilde{\tilde{\phi}}_{\alpha \beta_{c c}}=\sqrt{\frac{2}{3}} \underline{\phi}_{\alpha \beta_{c c}}
\end{array}\right.
$$

$\underline{\phi}_{\alpha \beta_{m}}$ and $\underline{\phi}_{\alpha \beta_{c c}}$ are magnetizing and leakage flux respectively. Then, the shortcircuit-current equation becomes

$$
\tilde{\tilde{i}}_{\alpha \beta_{c c}}=\frac{2}{3} \frac{\eta_{c c}}{R_{s}} Q\left(\theta_{c c}\right) \frac{\mathrm{d}}{\mathrm{d} t} \phi_{\alpha \beta_{m}}
$$

According to this equation, the faulty winding $B_{c c}$ becomes a simple unbalanced resistance element in parallel with magnetizing inductance. The existence of localization matrix $Q\left(\theta_{c c}\right)$ in (9) makes complex the state space representation in Concordia's axis. In a large range of industrial application, voltage drop in $R_{s}$ and $L_{f}$ is neglected according to stator voltage $\underline{u}_{\alpha \beta_{s}}$ then, we can put a short-circuit element $Q_{c c}$ in input voltage border (Figure 2). Line currents $\underline{i}_{\alpha \beta_{s}}$ become the sum of short-circuit current $\underline{\tilde{i}}_{\alpha \beta_{c c}}$ and usual current $\underline{i}_{\alpha \beta_{s}}^{\prime}$ in classical Concordia model.

It is much simpler to work in the rotor reference frame because we have only two stator variables to transform. Therefore, in state operation, all the variables have their pulsations equal to $s \omega_{s}$ (where $s$ is the slip and $\omega_{s}$ is stator pulsation). Park's

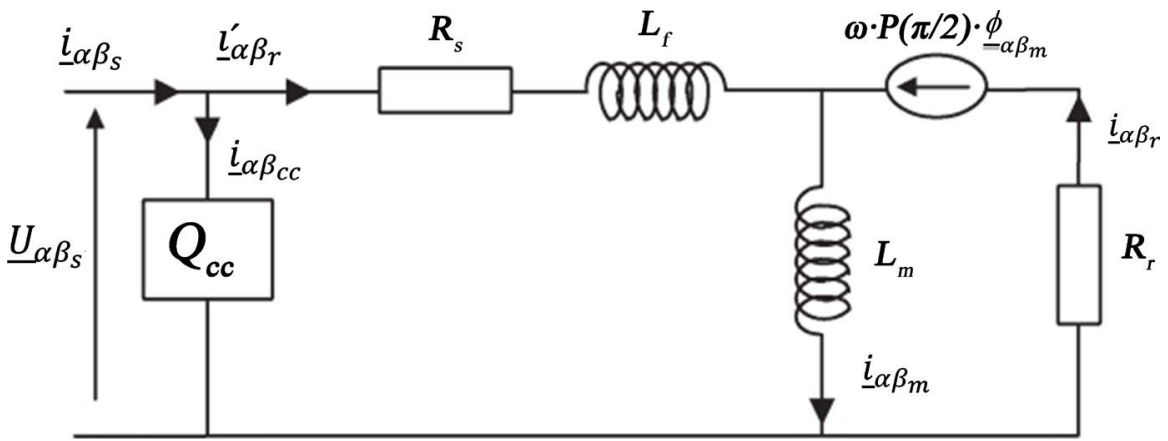

Figure 2. Short-circuit model of induction machine [30]. 
transformation is defined as

$$
\underline{\boldsymbol{X}}_{d q}=P(-\theta) \cdot \underline{\boldsymbol{X}}_{\alpha \beta}
$$

Afterward, the faulty model will be expressed under Park's reference frame. Therefore, short-circuit current (11) becomes

$$
\underline{\tilde{i}}_{d q_{c c}}=\frac{2}{3} \frac{\eta_{c c}}{R_{s}} P(-\theta) Q\left(\theta_{c c}\right) P(\theta) \underline{u}_{d q_{s}}
$$

\subsubsection{Global Stator Faulty Model}

Fundamentally, in faulty case, an induction machine can be characterized by two equivalent modes. The common mode model corresponds to the healthy dynamics of the machine (Park's model) whereas the differential mode model explains the faults.

We generalize this model by dedicating to each phase of the stator a short circuit element $Q_{c c_{k}}$ to explain a possible faulty winding. So, in presence of several short circuits, each faulty element allows the diagnosis of a phase by watching the value of the parameter. This simple deviation allows to indicate the presence of unbalance in the stator. Figure 3 shows the global stator faulty model in $d q$ Park's axis with global leakage referred to the stator.

Voltage and flux equations for faulty model with global leakage inductance referred to the stator can be written as:

- Park's model (stator and rotor)

$$
\left\{\begin{array}{l}
\underline{u}_{d q_{s}}=R_{s} \underline{i}_{d q_{s}}+\frac{\mathrm{d}}{\mathrm{d} t} \underline{\phi}_{d q_{s}}+\omega P\left(\frac{\pi}{2}\right) \underline{\phi}_{d q_{s}} \\
\underline{\phi}_{d q_{s}}=L_{f} \underline{i}_{d q_{s}}^{\prime}+L_{m}\left(\underline{i}_{d q_{s}}^{\prime}+\underline{i}_{d q_{r}}\right) \\
0=R_{r} \cdot \underline{i}_{d q_{r}}+\frac{\mathrm{d}}{\mathrm{d} t} \underline{\phi}_{d q_{r}} \\
\underline{\phi}_{d q_{r}}=L_{m}\left(\underline{i}_{d q_{s}}+\underline{i}_{d q_{r}}\right)
\end{array}\right.
$$

- Differential mode model (short-circuit currents)

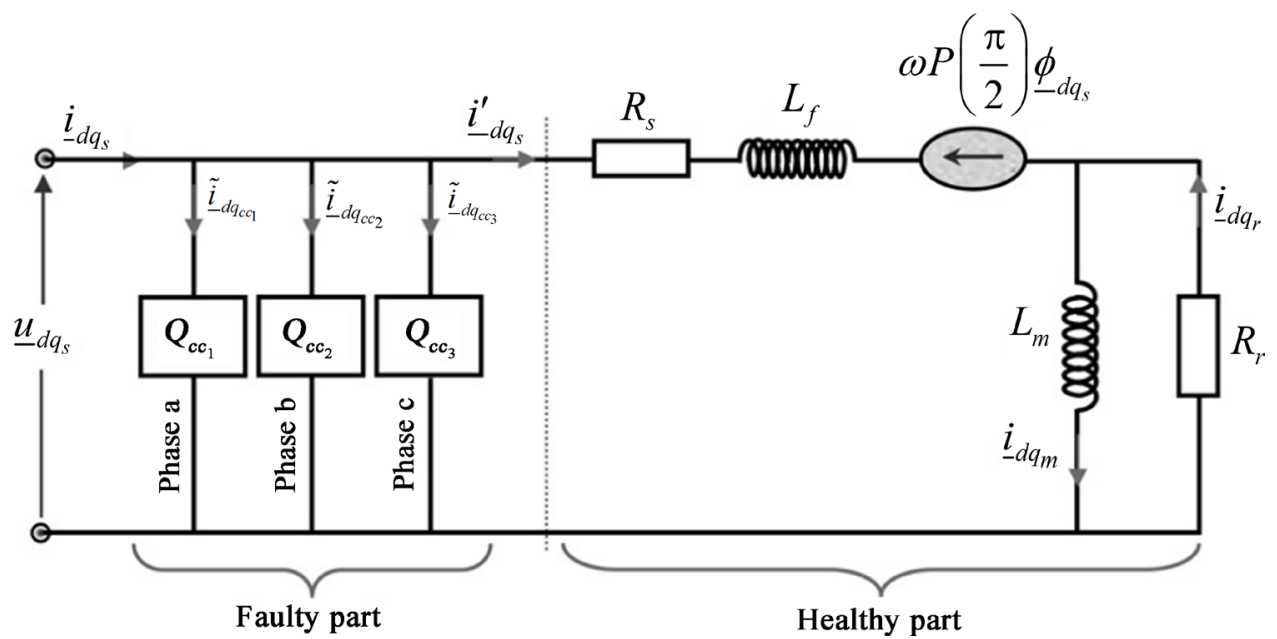

Figure 3. A global stator faulty model in $d q$ frame [30]. 


$$
\underline{\tilde{i}}_{d q_{c c_{k}}}=\frac{2}{3} \frac{\eta_{c c_{k}}}{R_{s}} P(-\theta) Q\left(\theta_{c c_{k}}\right) P(\theta) \underline{u}_{d q_{s}},
$$

Resultant $d q$ stator currents become

$$
\underline{i}_{d q_{s}}=\underline{i}_{d q_{s}}^{\prime}+\underline{\tilde{i}}_{d q_{c c_{k}}}={\underline{i^{\prime}}}_{d q_{s}}+\sum_{k=1}^{3} \underline{i}_{d q_{c c_{k}}}
$$

Each stator phase is characterized by its faulty parameters $\left(\eta_{c c_{k}}, \theta_{c c_{k}}\right)$, where $k$ indicates one of the three stator phases.

\subsubsection{State-Space Modelling of the Faulty Machine}

For simulation, it is necessary to write the faulty model in state-space representation. So, the fourth-order state-space representation of the IM with a winding fault is given by:

$$
\left\{\begin{array}{l}
\underline{\dot{x}}(t)=A(\omega) \underline{x}(t)+B \underline{u}(t) \\
\underline{y}(t)=C \underline{x}(t)+D \underline{u}(t)
\end{array}\right.
$$

where $\underline{x}(t)=\left[\begin{array}{llll}i_{d_{s}}^{\prime} & i_{q_{s}}^{\prime} & \phi_{d_{r}} & \phi_{q_{r}}\end{array}\right]^{\mathrm{T}}$ is the state-space vector; $\underline{u}(t)=\left[\begin{array}{ll}u_{d_{s}} & u_{q_{s}}\end{array}\right]^{\mathrm{T}}, \underline{y}(t)=\left[\begin{array}{ll}i_{d_{s}} & i_{q_{s}}\end{array}\right]^{\mathrm{T}}$ are the systems inputs-outputs. The matrices of Equation (17) are defined as follows:

$$
\begin{gathered}
A(\omega)=\left[\begin{array}{cccc}
-a & \omega & b \rho_{r} & b \omega \\
-\omega & -a & -b \omega & b \rho_{r} \\
R_{r} & 0 & -\rho_{r} & 0 \\
0 & R_{r} & 0 & -\rho_{r}
\end{array}\right] ; B=\left[\begin{array}{cccc}
b & 0 & 0 & 0 \\
0 & b & 0 & 0
\end{array}\right] ; C=\left[\begin{array}{cccc}
1 & 0 & 0 & 0 \\
0 & 1 & 0 & 0
\end{array}\right] \\
D=\left[\begin{array}{cc}
\frac{2}{3 R_{s}} \sum_{k=1}^{3} \eta_{c c_{k}} P(-\theta) Q\left(\theta_{c c_{k}}\right) P(\theta) & 0 \\
0 & 0
\end{array}\right] ;
\end{gathered}
$$

The inner parameters are as follows:

$$
\begin{gathered}
a=\frac{R_{s}+R_{r}}{L_{f}}, \quad b=\frac{1}{L_{f}}, \quad \rho_{r}=\frac{R_{r}}{L_{m}} \text { and } \eta_{c c_{k}}=\frac{N_{c c_{k}}}{N_{s}} \\
P(\theta)=\left[\begin{array}{cc}
\cos (\theta) & -\sin (\theta) \\
\sin (\theta) & \cos (\theta)
\end{array}\right] ; \\
Q\left(\theta_{c c_{k}}\right)=\left[\begin{array}{cc}
\cos ^{2}\left(\theta_{c c_{k}}\right) & \cos \left(\theta_{c c_{k}}\right) \sin \left(\theta_{c c_{k}}\right) \\
\cos \left(\theta_{c c_{k}}\right) \sin \left(\theta_{c c_{k}}\right) & \sin ^{2}\left(\theta_{c c_{k}}\right)
\end{array}\right] .
\end{gathered}
$$

$i_{d_{s}}, i_{q_{s}}$ are stator current components in $(d, q)$ frame while $\phi_{d_{r}}, \phi_{q_{r}}$ are rotor flux linkages current in $(d, q)$ frame. $\theta$ is the rotor position; $Q\left(\theta_{c c_{k}}\right)$ matrix depending on short-circuit angle $\theta_{c c_{k}} . R_{s}, L_{f}, R_{r}$ and $L_{m}$ are respectively, stator resistance, global leakage inductance referred to the stator, rotor resistance and magnetizing inductance.

\subsection{The PQ-MRAS Estimator Description}

The PQ-MRAS estimator method that consists to the association of P-MRAS and 
Q-MRAS estimators has been proposed by Bednarz and al. in Ref. 3. The PMRAS estimator is based on active power of IM and is used to estimate the stator resistance while the Q-MRAS estimator is based on reactive power used to estimate the rotor resistance. Each subsystem has its own independent mechanism based on a proportional-integral (PI) controller. The PQ-MRAS allows the simultaneous estimation of stator and rotor resistances (see Figure 4).

\subsubsection{P-MRAS Estimator}

In the P-MRAS estimator, the active power reference is given by:

$$
P_{r e f}=u_{s \alpha} i_{s \alpha}+u_{s \beta} i_{s \beta}
$$

and the adjustable model is given by:

$$
\begin{aligned}
P^{a d j} & =\operatorname{Re}\left\{u_{s}^{e s t} \cdot i_{s}^{*}\right\} \\
& =R_{s}^{e s t}\left(i_{s \alpha}^{2}+i_{s \beta}^{2}\right)+\sigma L_{s}\left(i_{s \alpha} \frac{\mathrm{d} i_{s \alpha}}{\mathrm{d} t}+i_{s \beta} \frac{\mathrm{d} i_{s \beta}}{\mathrm{d} t}\right)+\frac{L_{m}}{L_{r}}\left(i_{s \alpha} \frac{\mathrm{d} \psi_{r \alpha}^{e s t}}{\mathrm{~d} t}+i_{s \beta} \frac{\mathrm{d} \psi_{r \beta}^{e s t}}{\mathrm{~d} t}\right)
\end{aligned}
$$

In order to minimize the error between the reference and adjustable models using the adaptive mechanism, the resistance of the stator can be evaluated by the following equation:

$$
R_{s}^{e s t}=K_{P R_{s}} \varepsilon_{P}+K_{I R_{s}} \int \varepsilon_{P} \mathrm{~d} t
$$

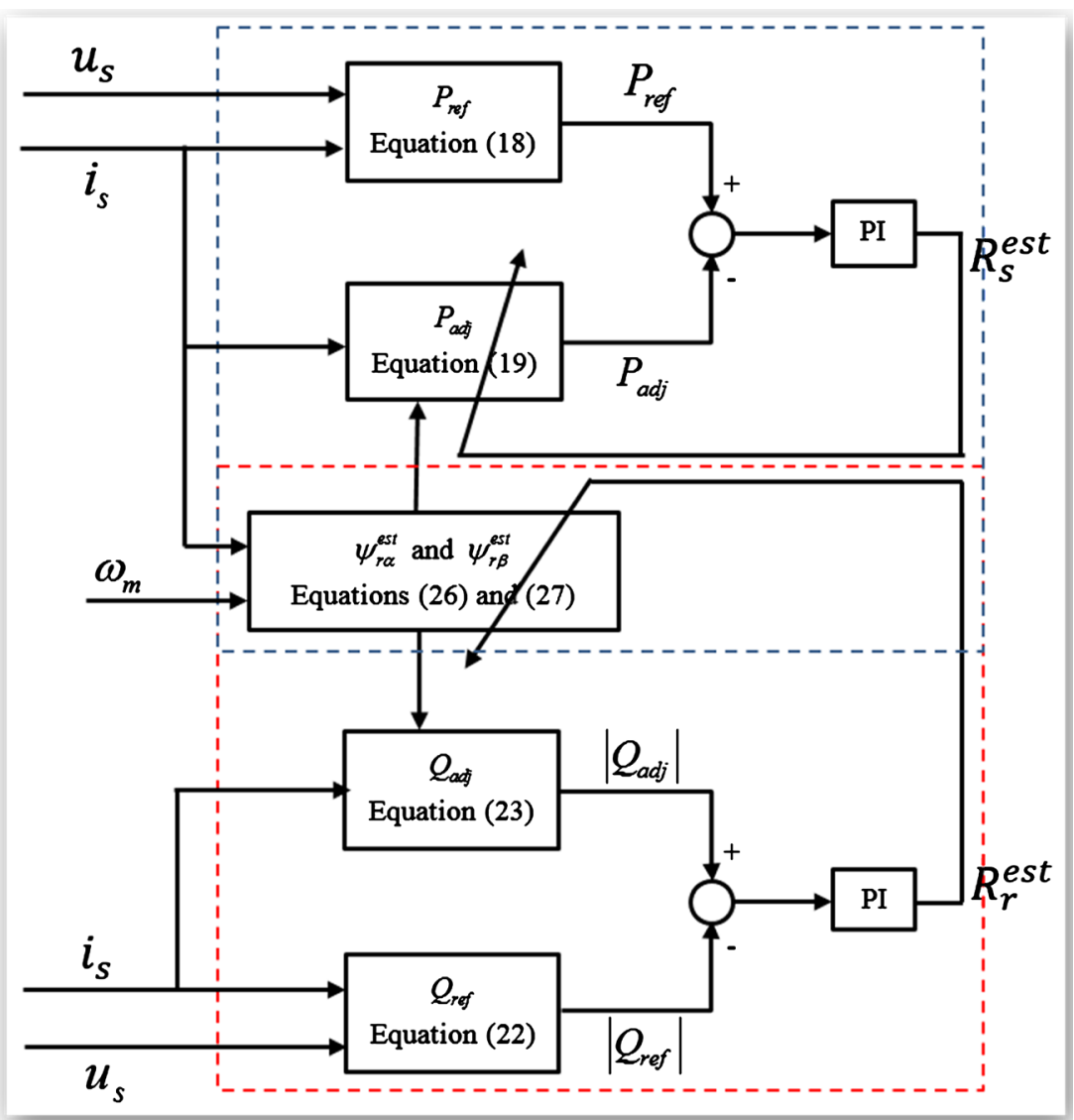

Figure 4. Block diagram of the PQ-MRAS estimator. 
with

$$
\varepsilon_{P}=P_{r e f}-P_{a d j}
$$

\subsubsection{Q-MRAS Estimator}

In the Q-MRAS estimator, the reactive power reference can be defined as follows:

$$
Q_{r e f}=u_{s \beta} i_{s \alpha}-u_{s \alpha} i_{s \beta}
$$

and the adjustable model is given by:

$$
Q_{a d j}=\sigma L_{s}\left(i_{s \alpha} \frac{\mathrm{d} i_{s \beta}}{\mathrm{d} t}-i_{s \beta} \frac{\mathrm{d} i_{s \alpha}}{\mathrm{d} t}\right)+\frac{L_{m}}{L_{r}}\left(i_{s \alpha} \frac{\mathrm{d} \psi_{r \beta}^{e s t}}{\mathrm{~d} t}-i_{s \beta} \frac{\mathrm{d} \psi_{r \alpha}^{e s t}}{\mathrm{~d} t}\right)
$$

In the case of Q-MRAS estimator, the resistance can be calculated by the equation:

$$
R_{r}^{e s t}=K_{P R_{r}} \varepsilon_{Q}+K_{I R_{r}} \int \varepsilon_{Q} \mathrm{~d} t
$$

with

$$
\varepsilon_{Q}=\left|Q_{\text {ref }}\right|-\left|Q_{a d j}\right|
$$

In this model, the current model for different axes $(\alpha, \beta)$ used for the rotor flux components is obtained from:

$$
\begin{aligned}
& \frac{\mathrm{d} \psi_{r \alpha}^{e s t}}{\mathrm{~d} t}=\frac{R_{r}}{L_{r}}\left(L_{m} i_{s \alpha}-\psi_{r \alpha}^{e s t}\right)-p \omega \psi_{r \beta}^{e s t} \\
& \frac{\mathrm{d} \psi_{r \beta}^{e s t}}{\mathrm{~d} t}=\frac{R_{r}}{L_{r}}\left(L_{m} i_{s \beta}-\psi_{r \beta}^{e s t}\right)+p \omega \psi_{r \alpha}^{e s t}
\end{aligned}
$$

\subsection{Formulation of Interconnected High-Gain Observer}

In the IHGO technique, the IM is seen as an interconnection of two subsystems, where each of the subsystems satisfies some required properties of observability. The observer used is constructed on the basis of electrical values including stator currents $\left(i_{s \alpha}, i_{s \beta}\right)$ and stator voltages $\left(u_{s \alpha}, u_{s \beta}\right)$ and returns the mechanical values including the rotor flux $\left(\psi_{r \alpha}, \psi_{r \beta}\right)$, speed rotor $\omega$ and load torque $T_{l}$. [27] [28]. The dynamical equations used to describe this observer are [3]:

$$
\left\{\begin{array}{l}
\frac{\mathrm{d} \psi_{r \alpha}}{\mathrm{d} t}=\frac{R_{r} L_{m}}{L_{r}} i_{s \alpha}-\frac{R_{r}}{L_{r}} \psi_{r \alpha}-p \omega \psi_{r \beta} \\
\frac{\mathrm{d} \psi_{r \beta}}{\mathrm{d} t}=\frac{R_{r} L_{m}}{L_{r}} i_{s \beta}-\frac{R_{r}}{L_{r}} \psi_{r \beta}+p \omega \psi_{r \alpha} \\
\frac{\mathrm{d} i_{s \alpha}}{\mathrm{d} t}=\frac{L_{r}}{M} u_{s \alpha}-\left(\frac{L_{r} R_{s}}{M}+\frac{L_{m}^{2} R_{r}}{M L_{r}}\right) i_{s \alpha}-\frac{L_{m} R_{r}}{M L_{r}} \psi_{r \alpha}+\frac{L_{m}}{M} p \omega \psi_{r \beta} \\
\frac{\mathrm{d} i_{s \beta}}{\mathrm{d} t}=\frac{L_{r}}{M} u_{s \beta}-\left(\frac{L_{r} R_{s}}{M}+\frac{L_{m}^{2} R_{r}}{M L_{r}}\right) i_{s \beta}-\frac{L_{m} R_{r}}{M L_{r}} \psi_{r \beta}-\frac{L_{m}}{M} p \omega \psi_{r \alpha} \\
\frac{\mathrm{d} \omega_{m}}{\mathrm{~d} t}=\frac{1}{J}\left(T_{e}-T_{l}\right) \\
\frac{\mathrm{d} T_{l}}{\mathrm{~d} t}=0
\end{array}\right.
$$


where $\left(\psi_{s \alpha}, \psi_{s \beta}\right)$ and $\left(\psi_{r \alpha}, \psi_{r \beta}\right)$ are the stator flux and rotor flux respectively. $\left(i_{s \alpha}, i_{s \beta}\right)$ and $\left(i_{r \alpha}, i_{r \beta}\right)$ represents respectively the stator and rotor currents. $\omega$ is the rotor speed. These parameters (flux, current and speed) are dynamics parameters of the system. The inputs control parameters are stator voltages $\left(u_{s \alpha}, u_{s \beta}\right)$. Among these parameters, we have a measurable $\left(i_{s \alpha}, i_{s \beta}, i_{r \alpha}, i_{r \beta}, \omega\right)$ and non-measurable $\left(\psi_{s \alpha}, \psi_{s \beta}, \psi_{r \alpha}, \psi_{r \beta}\right)$. Despite the dynamic parameters of the system we can also define another elements that helps in descriptions of the all system such as the, load torque $T_{l}$, stator and rotor resistances $\left(R_{s}, R_{r}\right)$, stator, rotor and mutual inductances $\left(L_{s}, L_{r}, L_{m}\right), p, J, T_{e}$ denotes respectively the number of pole pairs, the moment of inertia and the electromagnetic torque. $M=L_{r} L_{s}-L_{m}^{2}$ is a reduce constant parameter.

Considering the states involved in the implementation of the IHGO, Equation (28) can be rewritten in terms of two interconnected subsystems as [27] [28]:

$$
\begin{aligned}
\frac{\mathrm{d}}{\mathrm{d} t}\left(\begin{array}{c}
i_{s \alpha} \\
\omega \\
T_{l}
\end{array}\right) & =\left(\begin{array}{ccc}
0 & b p \psi_{r \beta} & 0 \\
0 & 0 & -\frac{1}{J} \\
0 & 0 & 0
\end{array}\right)\left(\begin{array}{l}
i_{s \alpha} \\
\omega \\
T_{l}
\end{array}\right)+\left(\begin{array}{c}
-\gamma i_{s \alpha}+a b \psi_{r \alpha}+m_{1} u_{s \alpha} \\
m\left(i_{s \beta} \psi_{r \alpha}-i_{s \alpha} \psi_{r \beta}\right) \\
0
\end{array}\right) \\
\frac{\mathrm{d}}{\mathrm{d} t}\left(\begin{array}{c}
i_{s \beta} \\
\psi_{r \alpha} \\
\psi_{r \beta}
\end{array}\right) & =\left(\begin{array}{ccc}
-\gamma & -b p \omega & a b \\
0 & -a & -p \omega \\
0 & p \omega & -a
\end{array}\right)\left(\begin{array}{c}
i_{s \beta} \\
\psi_{r \alpha} \\
\psi_{r \beta}
\end{array}\right)+\left(\begin{array}{l}
m_{1} u_{s \beta} \\
a L_{m} i_{s \alpha} \\
a L_{m} i_{s \beta}
\end{array}\right)
\end{aligned}
$$

with $a, b, \gamma, m$ and $m_{1}$ defined by:

$a=\frac{R_{r}}{L_{r}}, b=\frac{L_{m}}{M}, \gamma=\frac{L_{r} R_{s}}{M}+\frac{L_{m}^{2} R_{r}}{M L_{r}}, m=\frac{p L_{m}}{J L_{r}}, m_{1}=\frac{L_{r}}{M}$.

The two subsystems (29) and (30) can be represented in the following compact interconnected forms:

$$
\begin{aligned}
& \left\{\begin{array}{l}
\dot{X}_{1}=A_{1}\left(u, y, X_{2}\right) X_{1}+g_{1}\left(u, y, X_{1}, X_{2}\right) \\
y_{1}=C_{1} X_{1}
\end{array}\right. \\
& \left\{\begin{array}{l}
\dot{X}_{2}=A_{2}\left(u, y, X_{1}\right) X_{2}+g_{2}\left(u, y, X_{1}, X_{2}\right) \\
y_{2}=C_{2} X_{2}
\end{array}\right.
\end{aligned}
$$

where $A_{1}\left(u, y, X_{2}\right), A_{2}\left(u, y, X_{1}\right), g_{1}\left(u, y, X_{1}, X_{2}\right)$ and $g_{2}\left(u, y, X_{1}, X_{2}\right)$ are:

$$
\begin{gathered}
A_{1}\left(u, y, X_{2}\right)=\left(\begin{array}{ccc}
0 & b p \psi_{r \beta} & 0 \\
0 & 0 & -\frac{1}{J} \\
0 & 0 & 0
\end{array}\right), g_{1}\left(u, y, X_{1}, X_{2}\right)=\left(\begin{array}{c}
-\gamma i_{s \alpha}+a b \psi_{r \alpha}+m_{1} u_{s \alpha} \\
\frac{p L_{m}}{J L_{r}}\left(i_{s \beta} \psi_{r \alpha}-i_{s \alpha} \psi_{r \beta}\right) \\
0
\end{array}\right), \\
A_{2}\left(u, y, X_{1}\right)=\left(\begin{array}{ccc}
-\gamma & -b p \omega & a b \\
0 & -a & -p \omega \\
0 & p \omega & -a
\end{array}\right), g_{2}\left(u, y, X_{1}, X_{2}\right)=\left(\begin{array}{c}
m_{1} u_{s \beta} \\
a L_{m} i_{s \alpha} \\
a L_{m} i_{s \beta}
\end{array}\right),
\end{gathered}
$$

The states vectors $X_{1}$ and $X_{2}$ and the matrices $C_{1}, C_{2}, u$ and $y$ are defined by: 


$$
X_{1}=\left(\begin{array}{c}
i_{s \alpha} \\
\omega \\
T_{l}
\end{array}\right), X_{2}=\left(\begin{array}{c}
i_{s \beta} \\
\psi_{r \alpha} \\
\psi_{r \beta}
\end{array}\right), C_{1}=C_{2}=\left(\begin{array}{l}
1 \\
0 \\
0
\end{array}\right)^{\mathrm{T}}, u=\left(\begin{array}{l}
u_{s \alpha} \\
u_{s \beta}
\end{array}\right), y=\left(\begin{array}{c}
i_{s \alpha} \\
i_{s \beta}
\end{array}\right)
$$

By assumptions the signals $\left(u, X_{1}\right)$ and $\left(u, X_{2}\right)$ are regularly persistent and known for the subsystems (29) and (30) respectively, considering that the functions $g_{1}\left(u, y, X_{1}, X_{2}\right)$ and $g_{2}\left(u, y, X_{1}, X_{2}\right)$ are globally Lipschitz with respect to $X_{1}$ and $X_{2}$ and uniformly with respect to $(u, y)$, the observers of subsystems (29) and (30) are defined by [27] [28]:

$$
\left\{\begin{array}{l}
\dot{Z}_{1}=A_{1}\left(Z_{2}\right) Z_{1}+g_{1}\left(u, y, Z_{1}, Z_{2}\right)+\left(\Gamma S_{1}^{-1} C_{1}^{\mathrm{T}}+B_{2}\left(Z_{2}\right)\right)\left(y_{1}-\hat{y}_{1}\right)+\left(K C_{2}^{\mathrm{T}}+B_{1}\left(Z_{2}\right)\right)\left(y_{2}-\hat{y}_{2}\right) \\
\dot{S}_{1}=-\theta_{1} S_{1}-A_{1}^{\mathrm{T}}\left(Z_{2}\right) S_{1}-S_{1} A_{1}\left(Z_{2}\right)+C_{1}^{\mathrm{T}} C_{1} \\
\hat{y}_{1}=C_{1} Z_{1}
\end{array}\right.
$$

$$
\left\{\begin{array}{l}
\dot{Z}_{2}=A_{2}\left(Z_{1}\right) Z_{2}+g_{2}\left(u, y, Z_{1}, Z_{2}\right)+S_{2}^{-1} C_{2}^{\mathrm{T}}\left(y_{2}-\hat{y}_{2}\right) \\
\dot{S}_{2}=-\theta_{2} S_{2}-A_{2}^{\mathrm{T}}\left(Z_{1}\right) S_{2}-S_{2} A_{2}\left(Z_{1}\right)+C_{2}^{T} C_{2} \\
\hat{y}_{2}=C_{2} Z_{2}
\end{array}\right.
$$

where

$$
\begin{aligned}
& Z_{1}=\left(\begin{array}{c}
\hat{i}_{s \alpha} \\
\hat{\omega}_{m} \\
\hat{T}_{l}
\end{array}\right), Z_{2}=\left(\begin{array}{c}
\hat{i}_{s \beta} \\
\hat{\psi}_{r \alpha} \\
\hat{\psi}_{r \beta}
\end{array}\right), B_{1}\left(Z_{2}\right)=k m \Lambda_{1} \hat{\psi}_{r \alpha}, B_{2}\left(Z_{2}\right)=k m \Lambda_{2} \hat{\psi}_{r \beta}, \\
& \Lambda_{1}=\left(\begin{array}{c}
0 \\
0 \\
1
\end{array}\right), \Lambda_{2}=\left(\begin{array}{c}
0 \\
0 \\
-1
\end{array}\right), K=\left(\begin{array}{ccc}
-k_{c 1} & 0 & 0 \\
-k_{c 2} & 0 & 0 \\
0 & 0 & 0
\end{array}\right), K=\left(\begin{array}{lll}
1 & 0 & 0 \\
0 & 1 & 0 \\
0 & 0 & \alpha
\end{array}\right)
\end{aligned}
$$

The matrices $A_{1}\left(Z_{2}\right)$ and $A_{2}\left(Z_{2}\right)$ as well as the field vectors $g_{1}\left(u, y, Z_{1}, Z_{2}\right)$ and $g_{2}\left(u, y, Z_{1}, Z_{2}\right)$ are defined by:

$$
\begin{gathered}
A_{1}\left(Z_{2}\right)=\left(\begin{array}{ccc}
0 & b p \hat{\psi}_{r \beta} & 0 \\
0 & 0 & -\frac{1}{J} \\
0 & 0 & 0
\end{array}\right) ; A_{2}\left(Z_{2}\right)=\left(\begin{array}{ccc}
-\gamma & -b p \hat{\omega} & a b \\
0 & -a & -p \hat{\omega} \\
0 & p \hat{\omega} & -a
\end{array}\right) \\
g_{1}\left(u, y, Z_{1}, Z_{2}\right)=\left(\begin{array}{c}
-\gamma \hat{i}_{s \alpha}+a b \hat{\psi}_{r \alpha}+m_{1} u_{s \alpha} \\
m\left(\hat{i}_{s \beta} \hat{\psi}_{r \alpha}-\hat{i}_{s \alpha} \hat{\psi}_{r \beta}\right) \\
0
\end{array}\right) ; g_{2}\left(u, y, Z_{1}, Z_{2}\right)=\left(\begin{array}{c}
m_{1} u_{s \beta} \\
a L_{m} \hat{i}_{s \alpha} \\
a L_{m} \hat{i}_{s \beta}
\end{array}\right)
\end{gathered}
$$

In the observers, $\theta_{1}, \theta_{2}, k, k_{c 1}, k_{c 2}$ and $\alpha$ are positives constants. $S_{1}$ and $S_{2}$ are positive symmetric matrices obtained by solving the Lyapunov equations [27] [28].

\subsection{Direct Rotor Field Oriented Control Scheme}

During the estimation of the stator and rotor resistances, the IM have to be in controlled. In the present work, the controller implemented is the vector control 
and more precisely the direct rotor flux-oriented control (DRFOC). The principle of vector control is to equate the behavior of the asynchronous machine with that of a DC machine, i.e. a linear and decoupled model, which allows a linear and decoupled control between the flux and torque of IM [31]. In rotor flux-oriented strategy, the rotor flux orientation is defined as follows:

$$
\left\{\begin{array}{l}
\psi_{r q}=0 \\
\psi_{r d}=\psi_{r}
\end{array}\right.
$$

The constraint (31) imposed on the quadrate rotor flux component allows that, the rotor flux is controlled by the direct component of the stator current $i_{\text {sd }}$, whereas the electromagnetic torque is controlled by the quadrature component of the stator current $i_{s q}$.

For the implementation of the bloc diagram of DRFOC (see Figure 5), the rotor flux $\left(\psi_{r}\right)$, the electromagnetic torque $\left(T_{e}\right)$ and the electrical synchronous stator $\left(\omega_{s}\right)$ have to be estimated using the following equations:

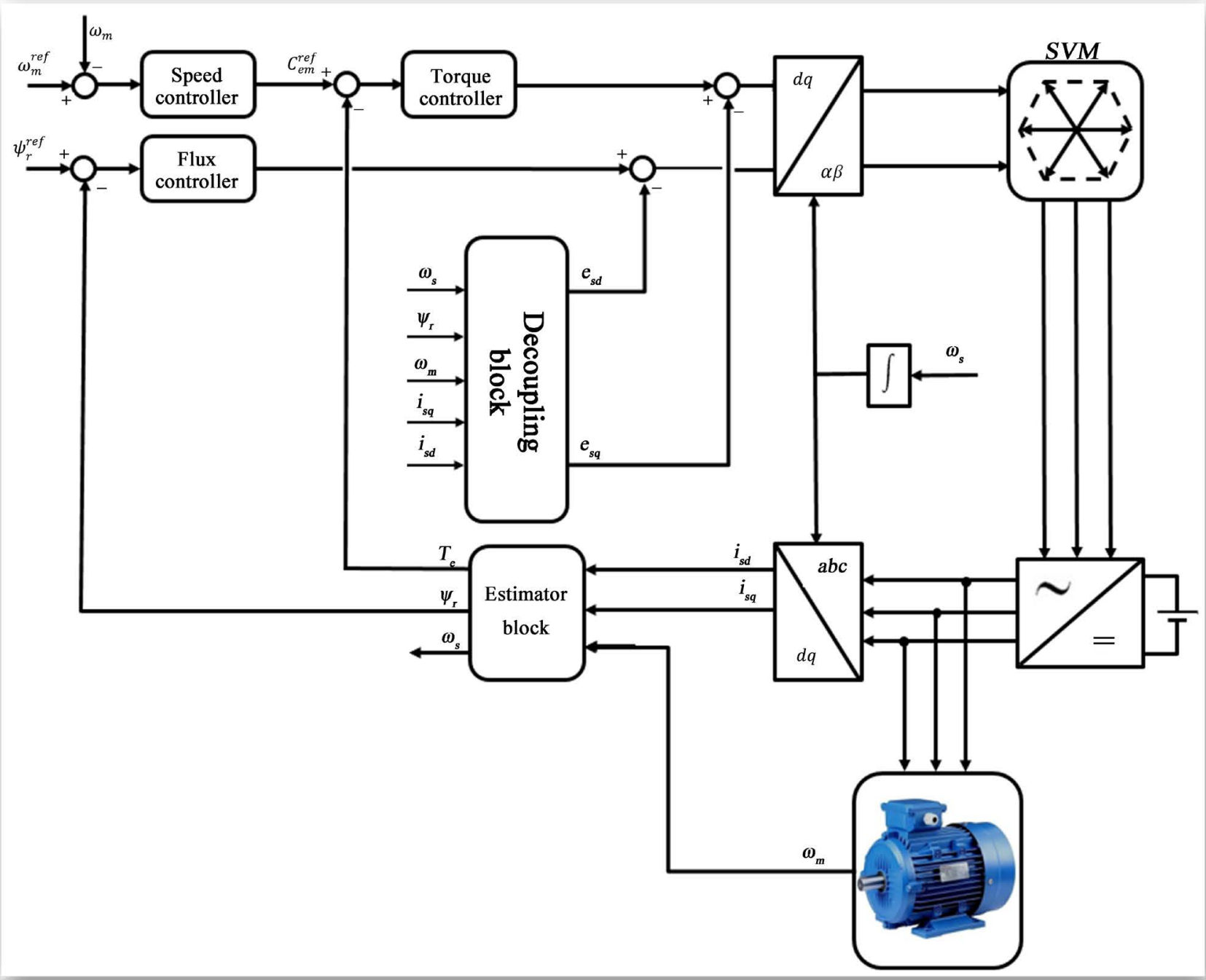

Figure 5. Scheme of DRFOC proposed. 


$$
\begin{gathered}
\psi_{r}=\int\left(\frac{R_{r}}{L_{r}}\left(L_{m} i_{s d}+\psi_{r}\right)\right) \mathrm{d} t \\
T_{e}=\frac{p L_{m}}{L_{r}} \psi_{r} i_{s q} \\
\omega_{s}=p \omega+\frac{R_{r}}{L_{r}} \frac{L_{m} i_{s q}}{\psi_{r}}
\end{gathered}
$$

The compensator terms $e_{s d}$ and $e_{s q}$ are defined by:

$$
\left\{\begin{array}{l}
e_{s d}=\omega_{s} \sigma L_{s} i_{s q}+\frac{L_{m} R_{r}}{L_{r}^{2}} \psi_{r} \\
e_{s q}=-\omega_{s} \sigma L_{s} i_{s d}-\frac{L_{m}}{L_{r}} p \omega \psi_{r}
\end{array}\right.
$$

\subsection{Algorithms for the Induction Motors' Faults Detection}

An ITSC fault detection algorithm is discussed in the paper. He cooperates with estimator of resistance. A general idea of a detection system is illustrated in Figure 6. The system is strictly related to the model-based fault detection approach [32] [33].

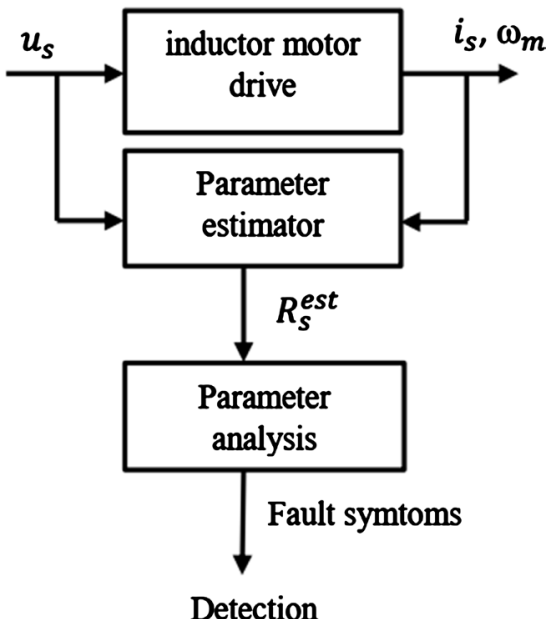

Figure 6. The main idea of the diagnostic system for IM drive.

It assumes, that ITSC results in a sharp decrease of the estimated stator resistance. Based on this hypothesis, the detection method is proposed, which uses a derivative of the estimated stator resistance:

$$
\text { If }\left|\frac{\mathrm{d}}{\mathrm{d} t} R_{s}^{\text {est }}\right| \geq \varepsilon_{r s} \text { then } 1 \text { else } 0
$$

where: $\varepsilon_{r s}$ threshold of a stator windings fault detection.

If the modulus of the derivative is equal of greater to the threshold the detector sends the logical 1, which indicates on occurring of ITSC.

\section{Results and Discussion}

Simulation tests were performed in the MATLAB/Simulink environment. The 
simulation results of the PQ-MRAS estimation of stator and rotor resistances with IHGO and the ITSC stator faults detection are presented in this section. In this work, the specific parameters of the induction motor used for simulations are given in Table 1 and in Table 2, the values of adaptation mechanism coefficients of PQ-MRAS estimators of stator and rotor resistances are presented.

Table 1. Induction machine parameters and its nominal values.

\begin{tabular}{cc}
\hline \multicolumn{1}{c}{ Model parameter } & \multicolumn{1}{c}{ Values } \\
\hline Parameters & $P_{n}=1.1 \mathrm{~kW}$ \\
Output power & $U_{s}=220 \mathrm{~V}$ \\
Stator voltage & $R_{s}=9.8 \Omega$ \\
Stator resistance & $R_{r}=5.3 \Omega$ \\
Rotor resistance & $L_{m}=0.5 \mathrm{H}$ \\
magnetizing inductance & $L_{f}=0.04 \mathrm{H}$ \\
global leakage inductance referred to the stator & $J=12.5 \times 10^{-3} \mathrm{~kg} \cdot \mathrm{m}^{2}$ \\
Inertia shaft & $p=2$ \\
Pole number & $N_{s}=464$ \\
\hline
\end{tabular}

Table 2. Coefficients of PI controllers in adaptation mechanism.

\begin{tabular}{cc}
\hline Symbol & Value \\
\hline$K_{P R_{s}}$ & 10 \\
$K_{I R_{s}}$ & 20 \\
$K_{P R_{r}}$ & 2 \\
$K_{I R_{r}}$ & 0.25 \\
\hline
\end{tabular}

\subsection{PQ-MRAS Estimation of Stator and Rotor Resistances with IHGO}

For the model described with our proposed technique, the results of the two modes of PQ-MRAS estimator are presented. First of all, the two modes of operation of the PQ-MRAS simulator with IHGO are presented, followed by the simulation results obtained for each mode.

\section{1) Operation modes of the PQ-MRAS simulator with IHGO}

The two modes are:

- Mode 1: the open-loop mode takes independently of control structure and observer (Figure 7(a));

- Mode 2: the open-loop mode takes independently of control structure but dependent of observer (Figure 7(b)).

\section{2) Simulation results}

In order to improve the PQ-MRAS estimator performance, tree groups of 

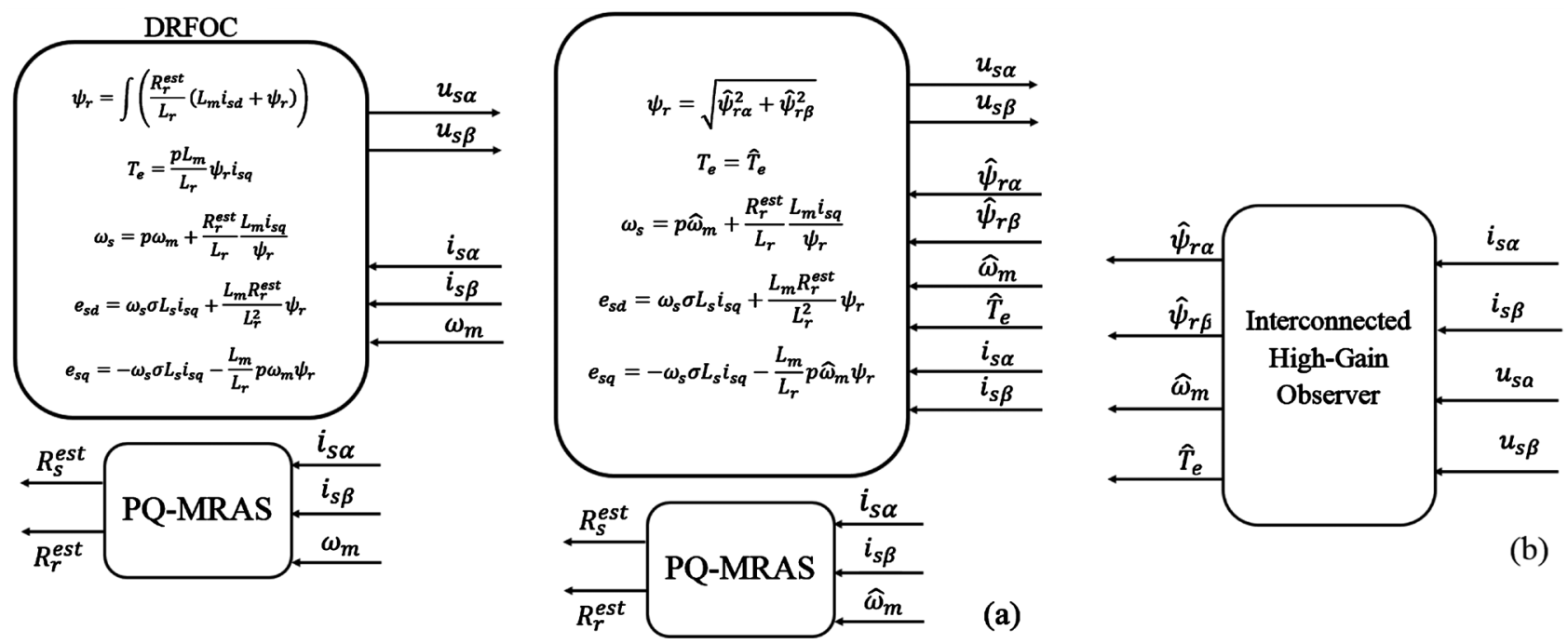

(b)

Figure 7. Open-loop modes operation of the PQ-MRAS estimator: (a) Mode 1, (b) Mode 2.

simulations will be carried for each mode. For the first group, simulation is carried out considering constant load torque with variable speed of rotor. The second group consider the constant speed of rotor with variable load torque. In the third group, speed and load torque are constant but with variations of stator's and rotor's resistances for different values of adaptive mechanism. In open-loop mode, the stator and rotor resistances estimated are not used. The control structure and IHGO depend on the nominal values of stator and rotor resistances. The results are presented in Figures 8-10.

The results of Figure 8 shows that, during the variations of rotational speed the estimated resistances by Mode 2 (using IHGO) are the same with these estimated by Mode 1 (using speed sensor). In both cases, it is observed a maximum relative error of $0.33 \%$. The explanation of this error can be found in the performance of the observer obtained by the reconstruction of the mechanical speed. From Figure 9, the results depict the estimations of stator and rotor resistances during the load torque variation. We clearly observe that, during the variations of load torque, the estimated resistances from Mode 2 (using IHGO) and Mode 1 (using speed sensor) shows the same loop in the steady states.

The results obtained by mode 2 show sensitivity to variations of the load torque taken as disturbances. This sensitivity is reflected in a very oscillating transient regime due to the behavior of the observer which no longer faithfully reconstructs the quantities that are used in the PQ-MRAS estimation during this laps of time. In addition, these results also show the robustness of the estimation using the observer with respect to a variation in load torque. Except for these transient periods, the two approaches (with and without a speed sensor) have almost equal estimated values.

Considering now the variations of the resistance of the rotor and of the stator simultaneously, the results of simulation for both resistances increased up to $150 \%$ of their nominal values (insert the value), which was related to the changes of 

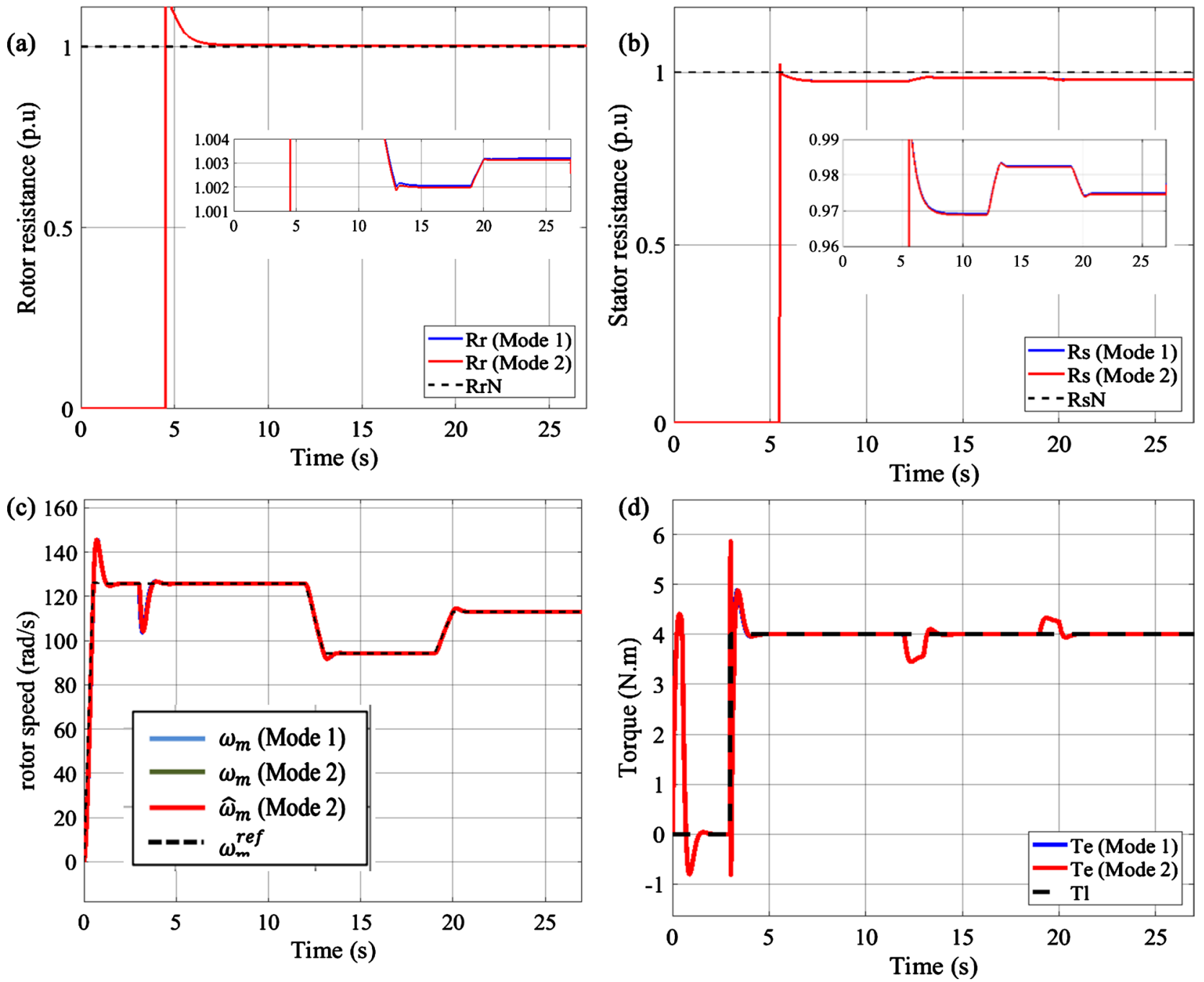

Figure 8. Operation in open-loop modes under rotational speed variation: (a) Rotor resistances estimated by mode 1 and mode 2 and nominal value; (b) Stator resistances estimated by mode 1 and mode 2 and nominal value; (c) reference, measured (mode 1 and 2) and observed rotational speed, (d) Load and electromagnetic (mode 1 and 2) torque
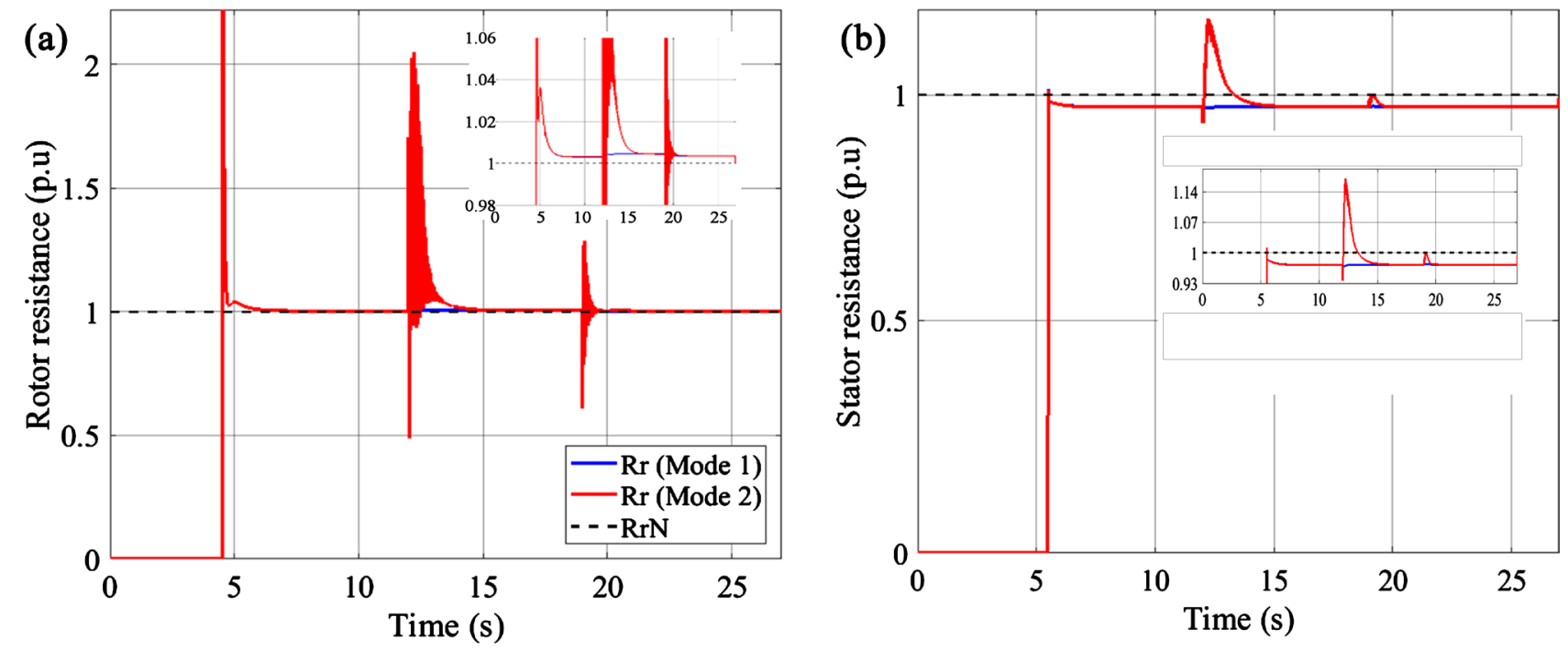

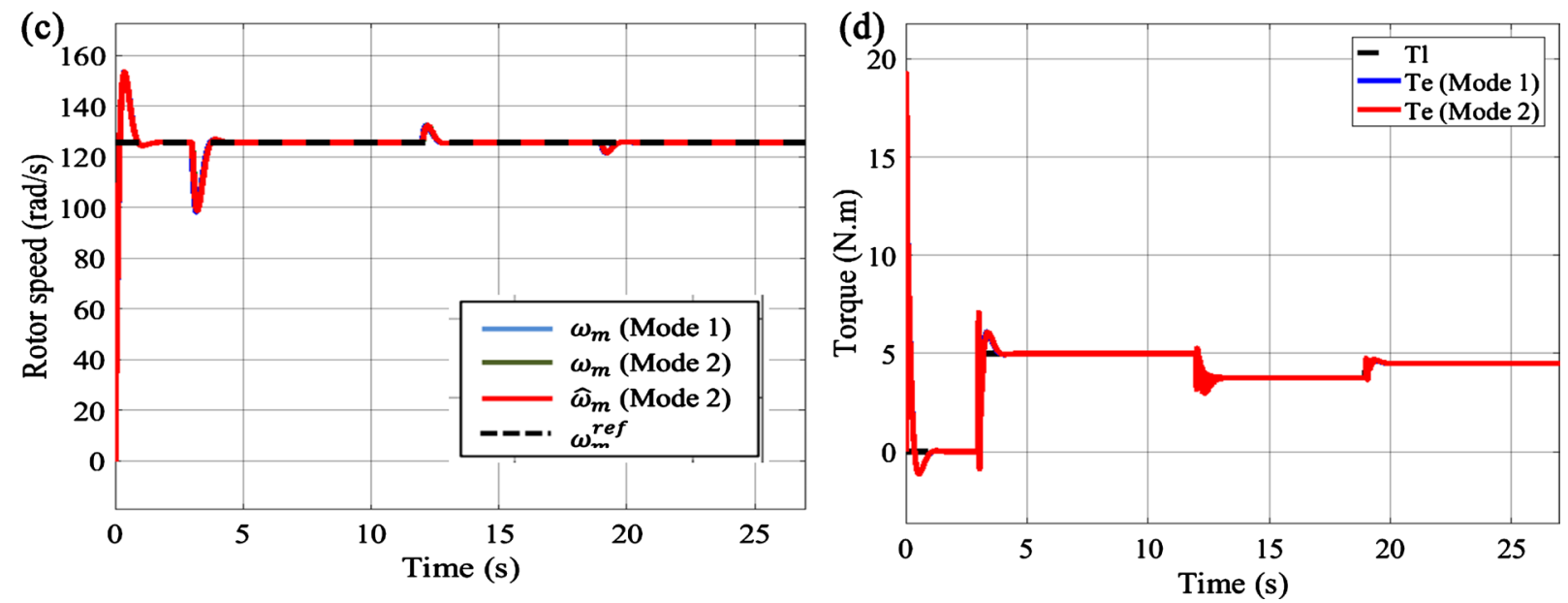

Figure 9. Operation in open-loop modes under load torque variation: (a) Rotor resistances estimated by modes 1 and 2 and nominal value; (b) Stator resistances estimated by modes 1 and 2 and nominal value; (c) reference, measured (modes 1 and 2 ) and observed rotational speed; (d) Load and electromagnetic (modes 1 and 2) torque.
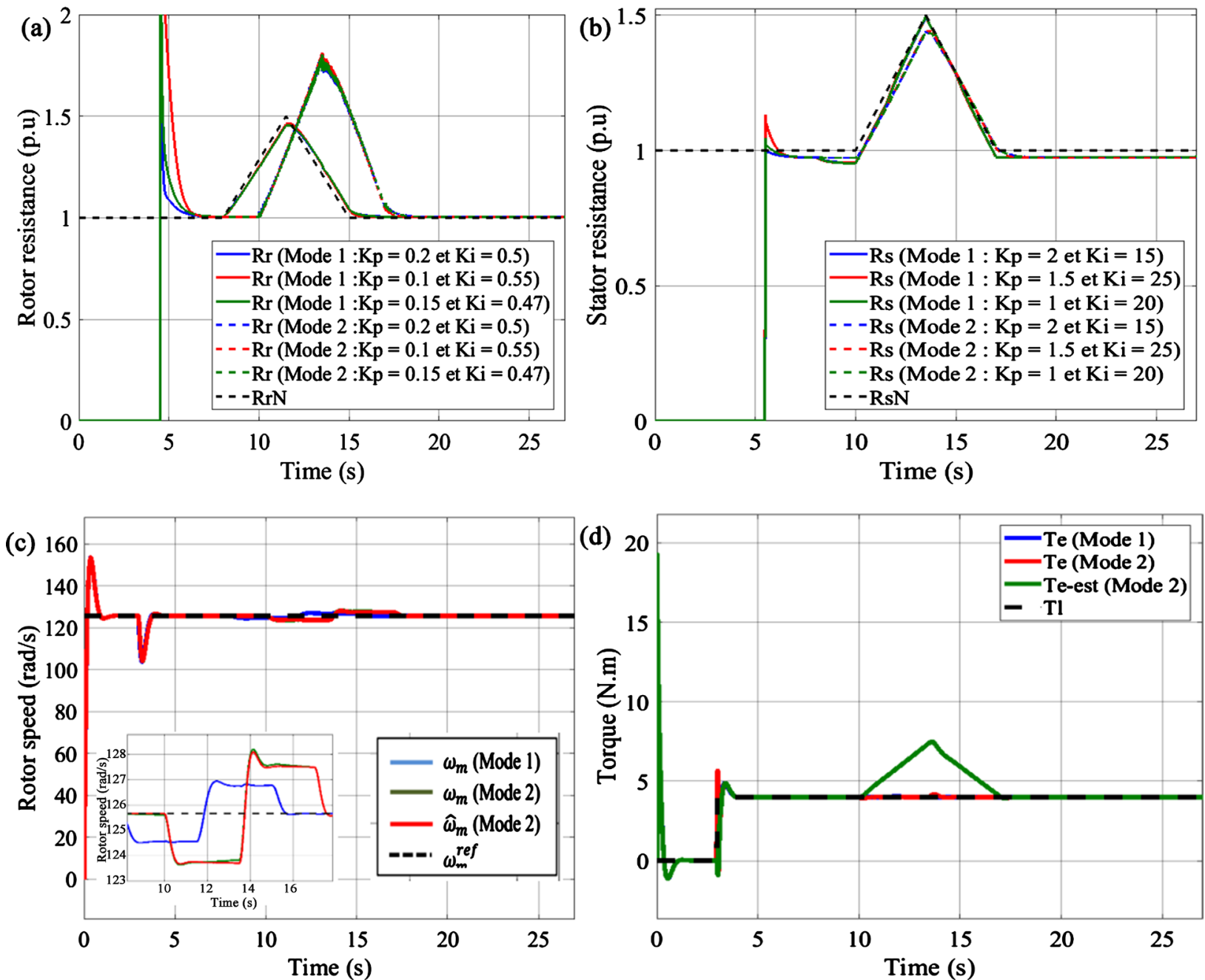

Figure 10. Operation in open-loop modes under resistances variation: (a) Rotor resistances estimated by modes 1 and 2 and nominal value; (b) Stator resistances estimated by modes 1 and 2 and nominal value; (c) reference, measured (mode 1 and 2 ) and observed rotational speed; (d) Load and electromagnetic (mode 1 and 2) Torque. 
machine windings temperatures (see Figure 10).

Regarding the results from Figure 10, the following observations are made; the PQ-MRAS estimator using the speed sensor estimates well the nominal values of the stator and of the rotor resistances taking into account their variations [3]. Similar performance is obtained with the PQ-MRAS estimator using IHGO for stator resistance estimation but not true in the case of rotor resistance. The technique proposed by Bednarz [3] remains better in this case.

\subsection{ITSC Stator Faults Detection}

\section{1) Impact of ITSC Fault}

The IM drive is considered to operate respectively in healthy and faulty mode. In order to observe the influence of the faults on the IM performances, IM starting at nominal voltage, with a sinusoidal three-phase balancing, takes place without load. The simulation for all the experiment is carried for a period of 10 seconds in the following conditions:

- At the time $t=1 \mathrm{~s}$ the machine is subjected to a nominal load torque $T_{l}=5 \mathrm{~N} \cdot \mathrm{m}$;

- At the time $t=3 \mathrm{~s}, 4 \mathrm{~s}, 5 \mathrm{~s}, 6 \mathrm{~s}, 7 \mathrm{~s}$ and $8 \mathrm{~s}$ a short-circuit of $N_{c c_{a}}=2,3,4,5,6$ and 7 windings are introduced on phase " $a$ ".

From the results showing in Figure 11 and Figure 12, for the three phase stator current $\left(i_{s a}, i_{s b}, i_{s c}\right)$, it is observed that the stator current becomes unbalanced with the current intensity in phase " $a$ " bigger than those in phases " $b$ " and " $c$ ". This increase occurs following a direct circular permutation. We also noticed that the greater the number of short-circuited turns, the greater the increase in currents. In addition to the current imbalance, we also notice an imbalance in the phase shifts shown in Figure 12. This phase shift is no longer equal to $120^{\circ}$ (healthy operation). The curves Figure 13 shows oscillations of the short-circuit currents $\left(i_{c c a}, i_{c c b}, i_{c c c}\right)$ which increase when the ITSC fault increases. From Figure 14 and Figure 15 respectively the rotor speed $\omega$ and electromagnetic torque

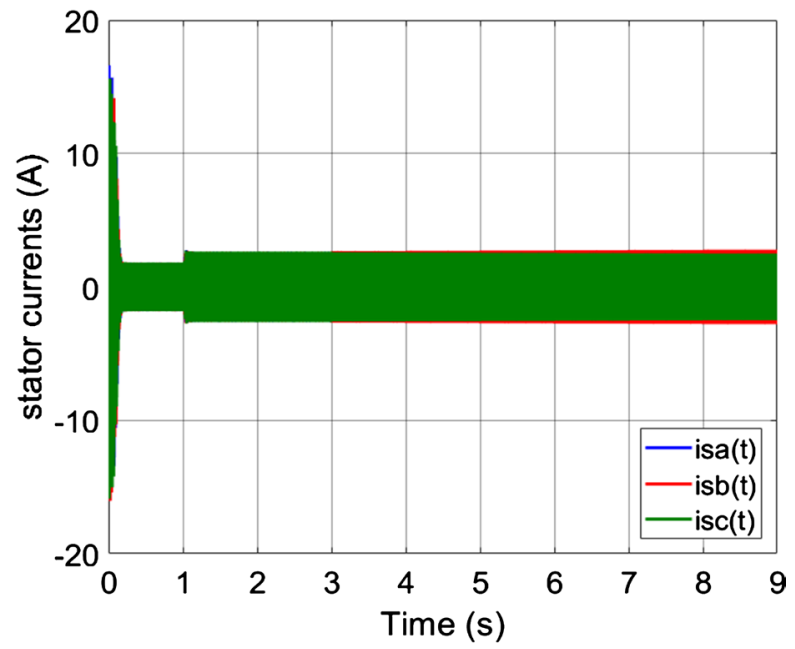

Figure 11 . Three phase stator currents $\left(i_{s a}, i_{s b}, i_{s c}\right)$ in healthy and faulty cases. 


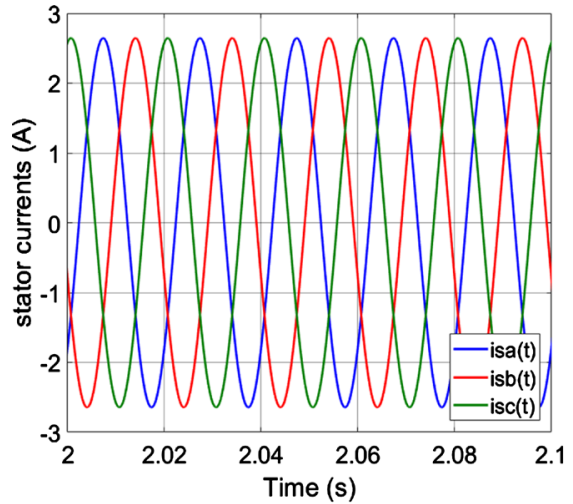

(a)

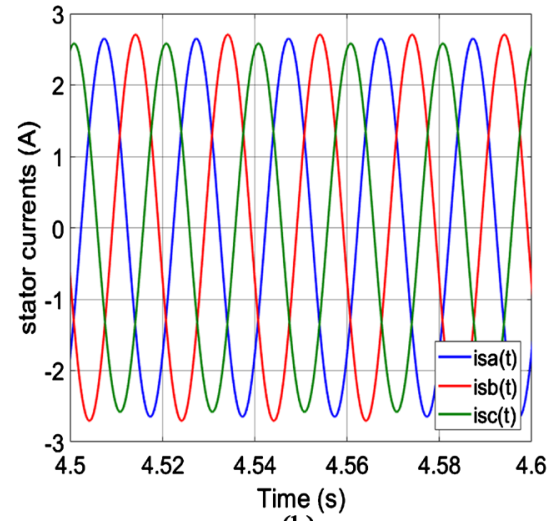

(b)

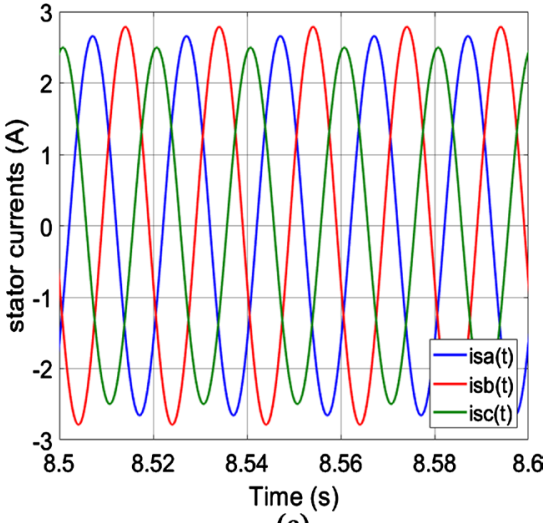

(c)

Figure 12. Zoom of $\left(i_{s a}, i_{s b}, i_{s c}\right)$ (a) before $t=3 \mathrm{~s}$ in healthy case; (b) between $4 \mathrm{~s}$ and $5 \mathrm{~s}$ with 4 turns short-circuits; (c) between 8 $s$ and $9 \mathrm{~s}$ with 7 turns short-circuits.

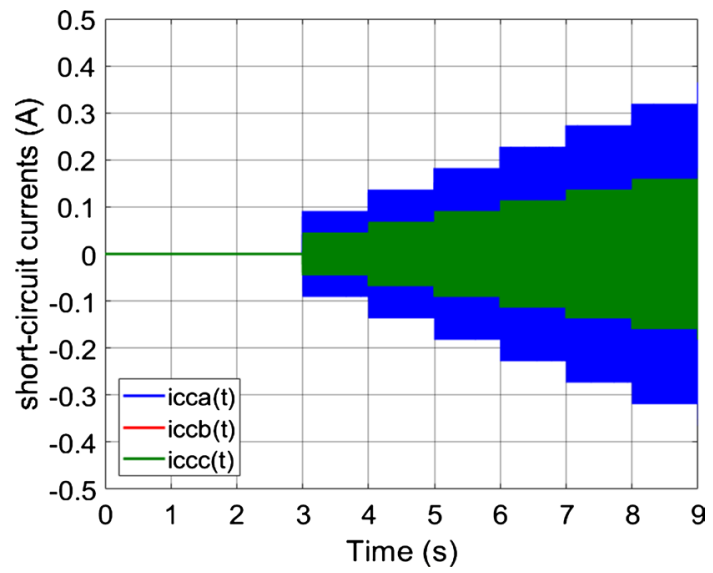

Figure 13. Short-circuit current $\left(i_{c c a}, i_{c c b}, i_{c c c}\right)$ in healthy and faulty cases.

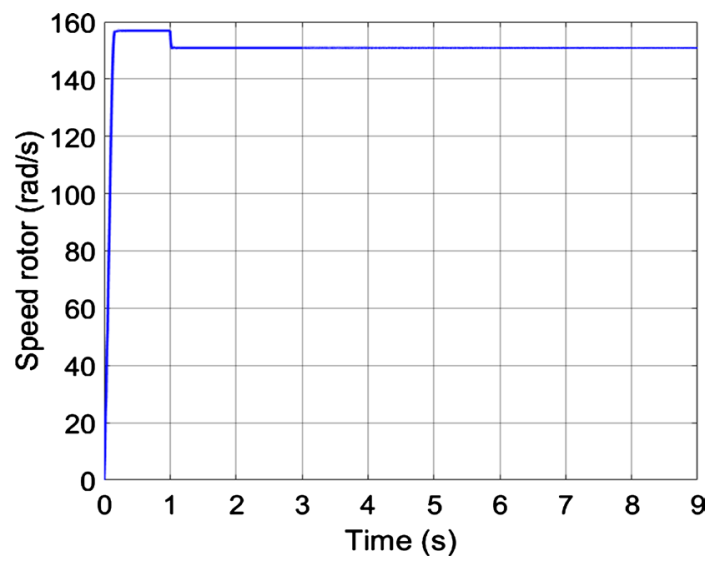

Figure 14. Rotor speed $\omega$ in healthy and faulty cases

$\left(T_{e}\right)$ variations give rise to the ITSC application that causes fluctuation in the rotor speed at high frequency.

\section{2) ITSC faults detection and isolation}

An ITSC in phase A of stator windings were simulated (moments of turns short and their amounts are marked on figures as arrows). Figure 16 and Figure 17 shows 


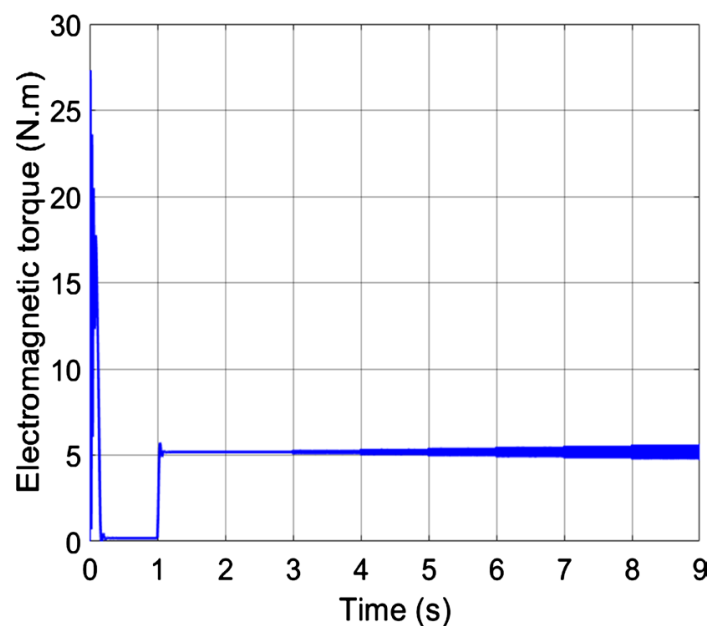

Figure 15. Electromagnetic $T_{e}$ in healthy and faulty cases.
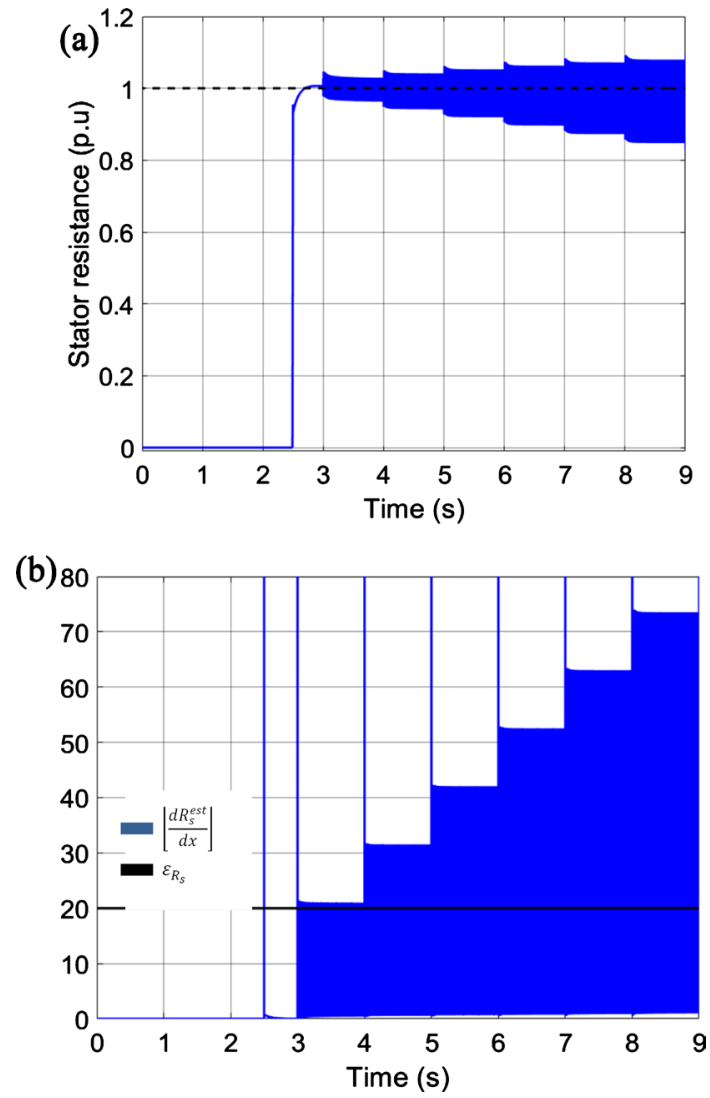

Figure 16. Stator winding resistance (a) and detector's signals (b) during ITSC in phase A; simulation results.

transients of the estimated stator resistance, signals from fault detector and stator current components. It can be observed, that the estimated stator resistance sharply decreases according to short circuits (Figure 16(a)). Consequently, it results in the stator's fault detector activation (Figure 16(c)) because the threshold value $\varepsilon_{R s}$ is exceeded by the modulus of estimated resistance derivative. The stator current increases due to ITSC and the amplitude level depends on the 

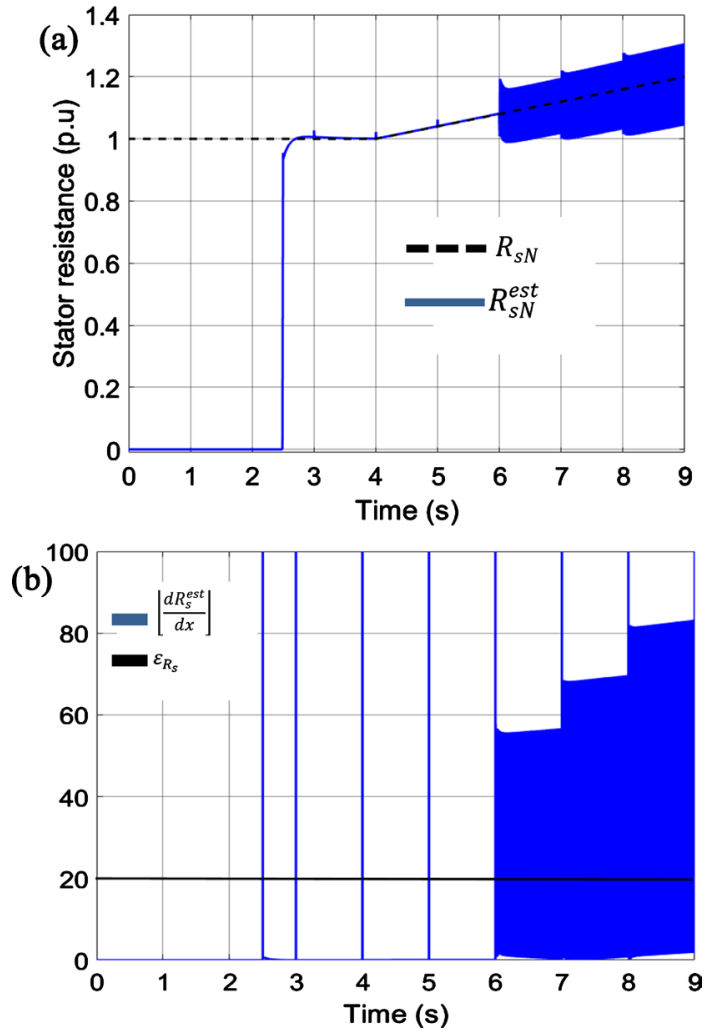

Figure 17. Stator winding resistance (a) and detector's signals (b) during simultaneous ITSC in phase A and heating process; simulation results.

fault severity (Figure 17).

It is evident that the value of the stator resistance varies as a result of heating (or cooling) of the machines' winding. It may result in incorrect performance of the fault detector. Therefore, other tests were carried out where a linear increase of the stator resistance was simulated up to $120 \%$ of the nominal value. Results are shown in Figure 16.

It can be noticed, that the derivative value doesn't exceed assumed threshold. It can be concluded that proposed stator fault detector is immune to thermal effects which are occurred in the machine. A study of the data shows that the number of short-circuited turns and the difference between the phase current of the healthy and faulty machine are related by expression of the form:

$$
N_{c c_{j}}=k\left(i_{s_{j}}^{\text {faulty }}-i_{s_{j}}^{\text {healthy }}\right)
$$

where $k=40.128$ is a coefficient of proportionality obtained from the results of the simulations. Figure 18 illustrates the reconstruction of the number of shortcircuited turns.

\section{Comparative Analysis}

Let's point out some promising results obtained in the literature using the similar approaches. Bednarz and Dybkowski [29] discussed the induction motor windings faults detection using flux-error based MRAS estimators. The authors de- 
signed estimators of IM parameters based on MRAS technique which are used to calculate rotor and stator resistances. Based on derivation algorithms, they used the obtained results in simple detection. The simulation and experimental studies are convergent what confirm usefulness of proposed systems. Some drawbacks can be point out such as the strongly dependence of MRAS estimators with many systems parameters. Thus, the authors do not consider a study of the data showing the impact of the number of short-circuited turns. A similar results were obtained by Bednarz et al., [3] using technique based on parameter estimation for identification of the stator faults in the induction motor drives using parameter estimator. Although the authors have obtained good results, the following

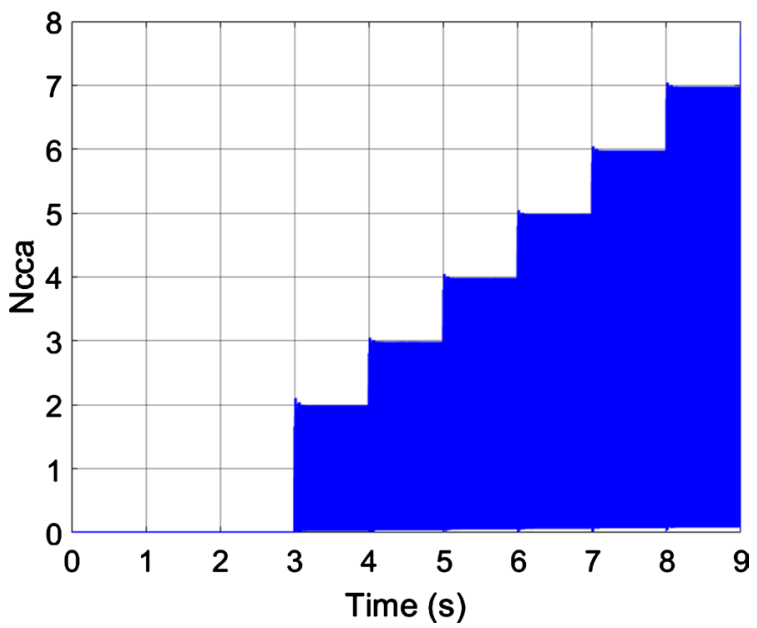

Figure 18. Determination of the number of short-circuited turns.

(a)

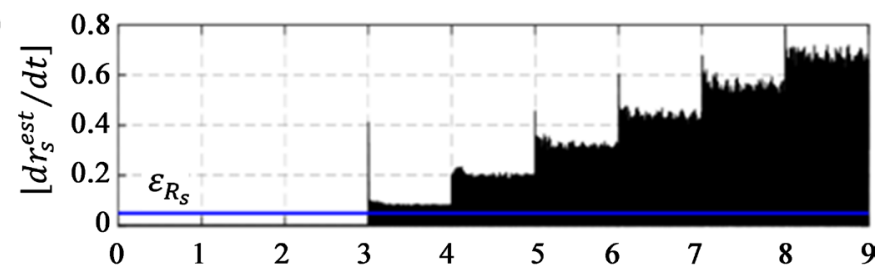

(b)

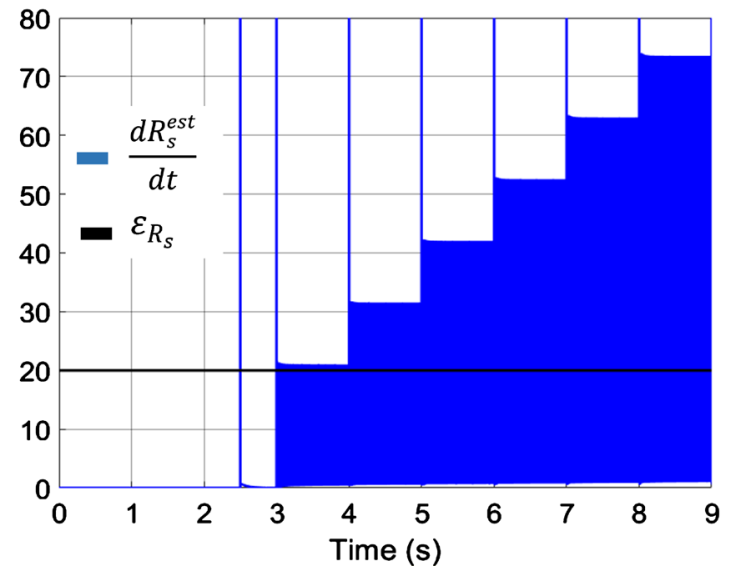

Figure 19. Qualitative comparison of the detector signal. (a) From Ref. [34], (b). Present work. 
remarks can be considered (a) the authors completely ignored the rotor resistance; (b) the complexity of the algorithm, in addition the authors fail to reconstruct efficiently the speed of the IM. An emblematic comparison can be made by viewing the Figure 19(a) obtained in Ref. [34] and Figure 19(b) proposed in this paper. It clearly appears that the proposed strategy can operate in the explosive default context (higher number of short-circuit turns). The control synthesis proposed in this work is the combination of many mathematical methods that is well understood and easily implementable in practice which is in good agreement from our theory analysis.

\section{Conclusions}

The estimation of induction motor parameters is a major area of research for sensorless drive, condition monitoring and fault diagnosis. It is proposed in this work an alternative strategy to the use of a speed sensor in the implementation of the PQ-MRAS estimator in order to calculate the rotor and stator resistances of an induction motor. The simulation results obtained from MATLAB/Simulink platform showed that the PQ-MRAS estimator using interconnected high-gain observer gives very similar results to those using the speed sensor. The estimation errors in the cases of speed and load torque variation are almost identical. The variations in stator and rotor resistances influence the performance of the observer and lead to a wrong estimation of the rotor resistance. This problem of the robustness of the observer with respect to rotor and stator resistances in the case of PQ-MRAS estimator provides a perspective for future work so that the observer can definitively and efficiently replace the physical speed sensor in the implementation of PQ-MRAS estimator. The derivation approach is exploited for ITSC fault detection in IM in order to show the impact of such fault on IM behavior; healthy and faulty IM models are established. Different fault scenarios and operation conditions are studied. Simulation results obtained are presented to highlight the performance and validity of the developed scheme. The analysis of the results allows the identification of the affected phase (by the faults) and show the sensitivity to ITSC fault occurrence. The system relies on the hypothesis that stator windings faults results in a sharp change of internal parameters' values of the motor, thus the observation and analysis of the results of the simulations allowed us to highlight the influence of the defects and thus giving the possibility of isolating them which deserves recognition as a profound contribution.

\section{Conflicts of Interest}

The authors declare no conflicts of interest regarding the publication of this paper.

\section{References}

[1] Guziński, J., Krzeminski, Z., Lewicki, A., Abu-Rub, H. and Diguet, M. (2013) Induction Motor Control Application in High-Speed Train Electric Drive. In: Giri, F., Ed., AC Electric Motors Control: Advanced Design Techniques and Applications, John 
Wiley \& Sons, Inc., Hoboken, 487-508. https://doi.org/10.1002/9781118574263.ch22

[2] Jurkovic, S., Rahman, K.M., Morgante, J.C. and Savagian, P.J. (2014) Induction Machine Design and Analysis for General Motors e-Assist Electrification Technology. IEEE Transactions on Industry Applications, 51, 631-639. https://doi.org/10.1109/TIA.2014.2330057

[3] Bednarz, S.A. and Dybkowski, M. (2019) Estimation of the Induction Motor Stator and Rotor Resistance Using Active and Reactive Power Based Model Reference Adaptive System Estimator. Applied Sciences, 9, 5145.

https://doi.org/10.3390/app9235145

[4] Zhao, L., Huang, J., Liu, H., Li, B. and Kong, W. (2014) Second-Order Sliding-Mode Observer with Online Parameter Identification for Sensorless Induction Motor Drives. IEEE Transactions on Industrial Electronics, 61, 5280-5289.

https://doi.org/10.1109/TIE.2014.2301730

[5] Bonnett, A.H. and Yung, C. (2008) Increased Efficiency versus Increased Reliability. IEEE Industry Applications Magazine, 14, 28-36.

https://doi.org/10.1109/MIA.2007.909802

[6] Nandi, S., Toliyat, H.A. and Li, X. (2005) Condition Monitoring and Fault Diagnosis of Electrical Motors-A Review. IEEE Transactions on Energy Conversion, 20, 719-729. https://doi.org/10.1109/TEC.2005.847955

[7] Gadoue, S.M., Giaouris, D. and Finch, J.W. (2013) Stator Current Model Reference Adaptive Systems Speed Estimator for Regenerating-Mode Low-Speed Operation of Sensorless Induction Motor Drives. IET Electric Power Applications, 7, 597-606. https://doi.org/10.1049/iet-epa.2013.0091

[8] Loron, L. and Laliberte, G. (1993) Application of the Extended Kalman Filter to Parameters Estimation of Induction Motors. 1993 Fifth European Conference on Power Electronics and Applications, Brighton, 13-16 September 1993, 85-90.

[9] Talla, J., Peroutka, Z., Blahnik, V. and Strejt, L. (2015) Rotor and Stator Resistance Estimation of Induction Motor Based on Augmented EKF. Proceedings of the 2015 International Conference on Applied Electronics, Pilsen, 6-7 September 2016, 8-9.

[10] Asfu, W.T. (2020) Stator Current-Based Model Reference Adaptive Control for Sensorless Speed Control of the Induction Motor. Journal of Control Science and Engineering, 2020, Article ID: 8954704.

[11] Kumar, R., Das, S., Syam, P. and Chattopadhyay, A.K. (2015) Review on Model Reference Adaptive System for Sensorless Vector Control of Induction Motor Drives. IET Electric Power Applications, 9, 496-511. https://doi.org/10.1049/iet-epa.2014.0220

[12] Vasic, V., Vukosavic, S.N. and Levi, E. (2003) A Stator Resistance Estimation Scheme for Speed Sensorless Rotor Flux Oriented Induction Motor Drives. IEEE Transactions on Energy Conversion, 18, 476-483. https://doi.org/10.1109/TEC.2003.816595

[13] Said, M.N. and Benbouzid, M.E.H. (1999) Induction Motors Direct Field Oriented Control with Robust On-Line Tuning of Rotor Resistance. IEEE Transactions on Energy Conversion, 14, 1038-1042. https://doi.org/10.1109/60.815025

[14] Kojabadi, H.M., Abarzadeh, M. and Farouji, S.A. (2013) Robust Stator Resistance Identification of an IM Drive Using Model Reference Adaptive System. Energy Conversion and Management, 65, 507-517. https://doi.org/10.1016/j.enconman.2012.06.020

[15] Teja, A.R., Chakraborty, C., Maiti, S. and Hori, Y. (2011) A New Model Reference 
Adaptive Controller for Four Quadrant Vector Controlled Induction Motor Drives. IEEE Transactions on Industrial Electronics, 59, 3757-3767. https://doi.org/10.1109/TIE.2011.2164769

[16] Basak, S., Teja, A.R., Chakraborty, C. and Hori, Y. (2013) A New Model Reference Adaptive Formulation to Estimate Stator Resistance in Field Oriented Induction Motor Drive. IECON2013-39th Annual Conference of the IEEE Industrial Electronics Society, Vienna, 10-13 November 2013, 8470-8475.

https://doi.org/10.1109/IECON.2013.6700554

[17] Mapelli, F.L., et al. (2014) A Rotor Resistance MRAS Estimator for EV Induction Motor Traction Drive Based on Torque and Reactive Stator Power: Simulation and Experimental Results. 2014 International Conference on Electrical Machines (ICEM), Berlin, 2-5 September 2014, 31-37. https://doi.org/10.1109/ICELMACH.2014.6960155

[18] Zhen, L. and Xu, L. (1998) Sensorless Field Orientation Control of Induction Machines Based on a Mutual MRAS Scheme. IEEE Transactions on Industrial Electronics, 45, 824-831. https://doi.org/10.1109/41.720340

[19] Cruz, S.M. and Cardoso, A.M. (2004) Diagnosis of Stator Inter-Turn Short Circuits in DTC Induction Motor Drives. IEEE Transactions on Industry Applications, 40, 1349-1360. https://doi.org/10.1109/TIA.2004.834012

[20] Zaky, M. (2008) Speed Sensorless Control of Induction Motor Drives (Review Paper). ACTA Electrothechnica, 49, 221-228.

[21] Rong, W.J. (2004) Backstepping Wavelet Neural Network Control for Indirect FieldOriented Induction Motor Drive. IEEE Transactions on Neural Networks, 15, $367-$ 381. https://doi.org/10.1109/TNN.2004.824411

[22] Morand, F. (2005) Techniques d'observation sans capteur de vitesse en vue de la commande des machines asynchrones. Thèse de doctorat, INSAL.

[23] Holtz, J. (2000) Is Sensorless Position Control of Standard Induction Motors a Feasible Technology. Proceeding of the Power Electronics and Motion Conference, Beijing, 15-18 August 2000, 21-32.

[24] Saheb, T. (2004) Commande Sans Capteur Mécanique de la Machine Asynchrone thèse de doctorat. Université de Nantes, IREENA.

[25] Schauder, C. (1989) Adaptive Speed Identification for Vector Control of Induction Motors without Rotational Transducers. IEEE Transactions on Industry Applications, 28, 1054-1061. https://doi.org/10.1109/28.158829

[26] Guezmil, A., Berriri, H., Pusca, R., Sakly, A., Romary, R. and Mimouni, M.F. (2017) Detecting Inter-Turn Short-Circuit Fault in Induction Machine Using High-Order Sliding Mode Observer: Simulation and Experimental Verification. Journal of Control, Automation and Electrical Systems, 28, 532-540. https://doi.org/10.1007/s40313-017-0314-2

[27] Traore, V., De Leon, J., Glumineau, A. and Loron, L. (2009) Adaptive Interconnected Observer for Sensorless Induction Motor. International Journal of Control, 82, 1627 1640. https://doi.org/10.1080/00207170802653719

[28] Ghanes, M., Barbot, J.B., De Leon, J. and Glumineau, A. (2010) A Robust Sensorless Output Feedback Controller of the Induction Motor Drives: New Design and Experimental Validation. International Journal of Control, 83, 484-497. https://doi.org/10.1080/00207170903193474

[29] Bednarz, S.A., Dybkowski, M. and Wolkiewicz, M. (2018) Identification of the Stator Faults in the Induction Motor Drives Using Parameter Estimator. 2018 IEEE 18th 
International Power Electronics and Motion Control Conference (PEMC), Budapest, 26-30 August 2018, 688-693. https://doi.org/10.1109/EPEPEMC.2018.8521893

[30] Bachir, S., Tnani, S., Trigeassou, J.C. and Champenois, G. (2006) Diagnosis by Parameter Estimation of Stator and Rotor Faults Occurring in Induction Machines. IEEE Transactions on Industrial Electronics, 53, 963-973.

https://doi.org/10.1109/TIE.2006.874258

[31] Kazmierkowski, M.P., Krishnan, R. and Blaabjerg, F. (2002) Control in Power Electronics. Academic press, San Diego, 579.

[32] Isermann, R. (2011) Fault-Diagnosis Applications: Model-Based Condition Monitoring: Actuators, Drives, Machinery, Plants, Sensors, and Fault-Tolerant Systems. Springer Science and Business Media, Berlin.

[33] Gao, Z., Cecati, C. and Ding, S.X. (2015) A Survey of Fault Diagnosis and Fault-Tolerant Techniques-Part I: Fault Diagnosis with Model-Based and Signal-Based Approaches. IEEE Transactions on Industrial Electronics, 62, 3757-3767.

https://doi.org/10.1109/TIE.2015.2417501

[34] Bednarz, S.A. and Dybkowski, M. (2019) Induction Motor Windings Faults Detection Using Flux-Error Based MRAS Estimators. Diagnostyka, 20, 87-96.

https://doi.org/10.29354/diag/109092 


\section{Abbreviations and Symbols}

PQ-MRAS Active (P) and reactive (Q) power Model Reference Adaptive System

IM Induction Motor

DRFOC Direct Rotor Field Oriented Control

$P \quad$ Active power

$Q \quad$ Reactive power

$u_{s} \quad$ Stator voltage vector

$i_{s} \quad$ Stator current vector

$i_{r} \quad$ Rotor current vector

$\phi_{s} \quad$ Stator electromagnetic flux vector

$\phi_{r} \quad$ Rotor electromagnetic flux vector

$\omega \quad$ Rotational shaft speed

$T_{e} \quad$ Electromagnetic torque

$T_{l} \quad$ Load torque

$R_{\varsigma} \quad$ Stator resistance

$R_{r} \quad$ Rotor resistance

$L_{s} \quad$ Stator inductance

$L_{r} \quad$ Rotor inductance

$L_{m} \quad$ Magnetizing inductance

$p \quad$ Number of pole pairs

$J \quad$ Shaft inertia

$P^{\text {est }} \quad$ Estimation error of the active power

$Q^{e s t} \quad$ Estimation error of the reactive power

$K_{P R_{S}} \quad$ Coefficient of the proportional term in the stator resistance adaptation mechanism

$K_{I R_{s}} \quad$ Coefficient of the integral term in the stator resistance adaptation mechanism

$K_{P_{r}} \quad$ Coefficient of the proportional term in the rotor resistance adaptation mechanism

$K_{I R_{r}} \quad$ Coefficient of the integral term in the rotor resistance adaptation mechanism 